\title{
IMPLICANCIAS Y REFLEXIONES DEL IMPACTO DE AGENTES MICROBIOLÓGICOS EN CERÁMICAS ARQUEOLÓGICAS A PARTIR DE UN ESTUDIO DE CASO (NORTE DE LA PROVINCIA DE LA RIOJA, ARGENTINA)
}

\author{
IMPLICATIONS AND REFLECTING ON THE IMPACT OF MICROBIOLOGIC AGENTS \\ ON ARCHAEOLOGICAL POTTERY FROM A CASE STUDY \\ (NORTHERN LA RIOJA PROVINCE, ARGENTINA)
}

\author{
Daiana M. Soto ${ }^{1}$
}

Recibido 7 octubre 2019. Aceptado 12 mayo 2020

\begin{abstract}
Resumen: El estudio del biodeterioro del patrimonio cultural es una línea de trabajo que poco ha sido abordada desde una perspectiva arqueológica. Sin embargo, investigaciones arqueométricas recientes en materiales cerámicos apuntan a diversidad de agentes biológicos involucrados en un complejo proceso de deterioro mecánico, químico y estético en las superficies externas, internas y al interior de la pasta, presentando una relación sinérgica con la meteorización, la erosión y los agentes postdepositacionales in situ en los materiales cerámicos arqueológicos del norte de provincia de La Rioja (Argentina). Las propiedades físicas y químicas de estos materiales los convierten en bioreceptivos para la colonización microbiológica en ambientes con marcada tendencia a la aridez. Además, se reconoció el impacto de estas especies en la preservación del material y para la salud de investigadores. El objetivo de este manuscrito es discutir y reflexionar sobre las implicancias de la colonización microbiológicas en los materiales cerámicos arqueológicos estudiados. Se problematizan los potenciales sesgos en la preparación de muestras y obtención de datos arqueométricos y se destaca su contribución como línea de evidencia complementaria para estudios de procesos de formación de sitios arqueológicos, paleoambiente y circulación de objetos y/o materias primas.
\end{abstract}

Palabras clave: biodeterioro, bioindicadores, cerámica arqueológica, ambientes áridos, arqueometría.

\begin{abstract}
Cultural heritage biodeterioration is an actual research line that it has been poorly studied from an archaeological perspective. However, current archaeometric investigations in pottery materials point to a diversity of biological agents involved in a complex mechanical, chemical and fouling deterioration process of the external and inner surfaces and the paste, presenting a sinergetic relationship in situ by weathering, erosion and postdepositacional agents in archaeological pottery materials from Northern La Rioja province, Argentina. Physical and chemical properties of these materials make them bioreceptive for microbiological colonization in environments with a strong aridity. Besides, these species impact for pottery materials preservation and for investigators health care was recognized. The aim of this work is to discuss and reflect about microbiological colonization implications in the archaeological pottery materials studied. Potential bias in archaeometric sample preparation and data collection is pondered and, these agents contribution as a complementary evidence lines in archaeological sites formation process, paleoenvironment and objects and/or raw materials circulation is enlighten.

Keywords: biodeterioration, bioindicators, archaeological pottery, arid environments, archaeometric.
\end{abstract}

\section{Introducción}

Investigaciones desarrolladas en las últimas décadas han reconocido infinidad de agentes microbiológicos colonizando el patrimonio cultural e identificado tipos de deterioros y sus particulares alteraciones. Se ha destacado la complejidad del biodeterioro, la posibilidad de la presencia de agentes patógenos y la pérdida invaluable que ocasiona sobre el patrimonio cultural y materiales industriales (Allsopp et al., 2004; Blanchette, 2000; Jans, 2008; Jans et al., 2004; Moskal et al., 2014; Rose, 1981; Sánchez del Junco et al., 1992; Sterflinger, 2010; Sterflinger \& Piñar, 2012; St. Clair \& Seaward, 2004; Strzelczyk et al., 1997; Videla \& Giudice, 2000; Verran, 2013; Warcheid \& Braams, 2000). Estos estudios, en algunos casos, contribuyeron a la creación de proyectos de puesta en valor de sitios arqueológicos e históricos que contemplan como controlar dichos agentes (Altieri et al., 1999; Nishiura et al., 1994; Silvers \& Wolbers, 2004, entre otros). No obstante, poco se ha desarrollado qué implica la pérdida del patrimonio cultural y cómo afecta a las investigaciones científicas presentes y futuras, debido a que la perspectiva que ha abordado estos estudios es principalmente biológica.

Una de las primeras definiciones de biodeterioro plantea que, cualquier cambio indeseable en las propiedades de un material cultural debido a la actividad vital de microorganismos (Hueck, 1968). En principio, no hay restricciones en qué tipo de seres vivos pueden verse involucrados en tanto es un proceso natural de degradación (Gaylarde, 2013; Soto, 2019). No obstante, dependiendo del tipo de material cultural (inorgánico u orgánico) que afecten y de las condiciones ambientales involucradas, variarán los agentes biológicos presentes y el tipo de daño predominante (mecánico, químico o estético, también llamado suciedad en las superficies y/o biofouling) y, con este, las

1 Proyecto ArqueoLab-UBA - Instituto de Arquelogía, Facultad de Filosofía y Letras, Universidad de Buenos Aires (FFyL, UBA). 25 de Mayo 217 (1002), CABA, Buenos Aires - daiana.m.soto@gmail.com 
alteraciones fisicoquímicas y mecánicas ocasionadas (Allsopp et al., 2004; Rose, 1981; Verran, 2013; Valgañón, 2008). Este proceso siempre implica la presencia de microorganismos en una compleja relación simbiótica entre la interfase del material y el medio ambiente que, bajo determinadas condiciones climáticas pueden generar biopelículas (biofilms), comunidades microbianas complejas rodeadas por una matriz de sustancias poliméricas extracelulares (SPE) que producen el debilitamiento o pérdida de la estructura del material y el biofouling (Allsopp et al., 2004; De los Ríos et al., 2009; Gorbushina \& Broughton, 2009; Gorbushina, 2007; Rose, 1981; Verran, 2013, entre otros). Estas condiciones climáticas son más restrictivas para los microorganismos que colonizan materiales inorgánicos, debido a que carecen en su estructura elemental del carbono, nutriente vital (Rose, 1981). Razón por la cual los materiales orgánicos son más susceptibles a ser biodeteriorados (Allsopp et al., 2004; Valgañón, 2008).

Las recientes investigaciones sistemáticas sobre la incidencia de este proceso en los materiales cerámicos arqueológicos del norte de Famatina (La Rioja, Argentina) (Soto, 2015, 2019; Soto \& Guiamet, 2017; Soto et al., 2017, 2019, 2020; Guiamet et al., 2019), han sido enfocadas desde una perspectiva analítica. Se han identificado agentes microbiológicos afectando la preservación del material y pudiendo afectar la salud de investigadores (Soto, 2019). Asimismo, estos estudios han evidenciado la presencia de agentes microbiológicos en los procesos de formación de sitios arqueológicos en ambientes áridos. Una reflexión sobre la aplicabilidad de la conservación preventiva a estos materiales demostró que existe una tendencia a sólo considerar algunos factores indirectos de deterioro (sensu Michalski, 2006) como causales etológicos de la colonización biológica en el caso de los materiales inorgánicos (Soto \& Guiamet, 2017).

El objetivo de este escrito es problematizar aspectos del impacto del biodeterioro y evaluar sus implicancias en cerámicas arqueológicas a partir de un estudio de caso en el valle Antinaco, La Rioja, Argentina (Soto, 2019). Se reflexionan los alcances que el estudio de los agentes microbiológicos puede tener en las investigaciones arqueológicas y enfatizan aspectos que podrían afectar la preparación de muestras para análisis arqueométricos y la interpretación de sus resultados.

\section{Presentación del caso de estudio}

Área de estudio

Se localiza en la localidad arqueológica La Cuestecilla, sector noroccidental del valle de Antinaco, al pie de la Sierra Paimán, norte de la provincia de La Rioja (Argentina). Comprende la quebrada de Chañarmuyo y Angulos y se extiende a lo largo de las márgenes del río Chañarmuyo-Pituil por al menos $20 \mathrm{~km}$ del curso de este río (Callegari et al., 2013, 2015; Gonaldi et al., 2008) (Figura 1). A pesar de que ha sido intensamente afectada por la construcción de una acequia, la Ruta Provincial N³9 y el puente sobre el río Chañarmuyo, la localidad presenta en general un buen estado de conservación. Se ha identificado un sitio principal denominado La Cuestecilla (LC) de complejidad interna diferenciada (espacios residenciales, productivos, públicos y semi-públicos), aldeas que lo circundan que replican a menor escala sus patrones arquitectónicos, estructuras productivas, arte rupestre (Callegari et al., 2017) y geoglifos (Callegari et al., 2019). Además del ya nombrado Pukará de Chañarmuyo (PC) (De la Fuente, 1972, 2002) en la quebrada homónima.

En consonancia con los materiales recuperados y las diversas investigaciones realizadas, los sitios arqueológicos de esta localidad han sido adscriptos a la sociedad Aguada Meridional circa 550 al 1200 d.C. No obstante, es importante señalar que algunos sectores de LC presentan evidencia de

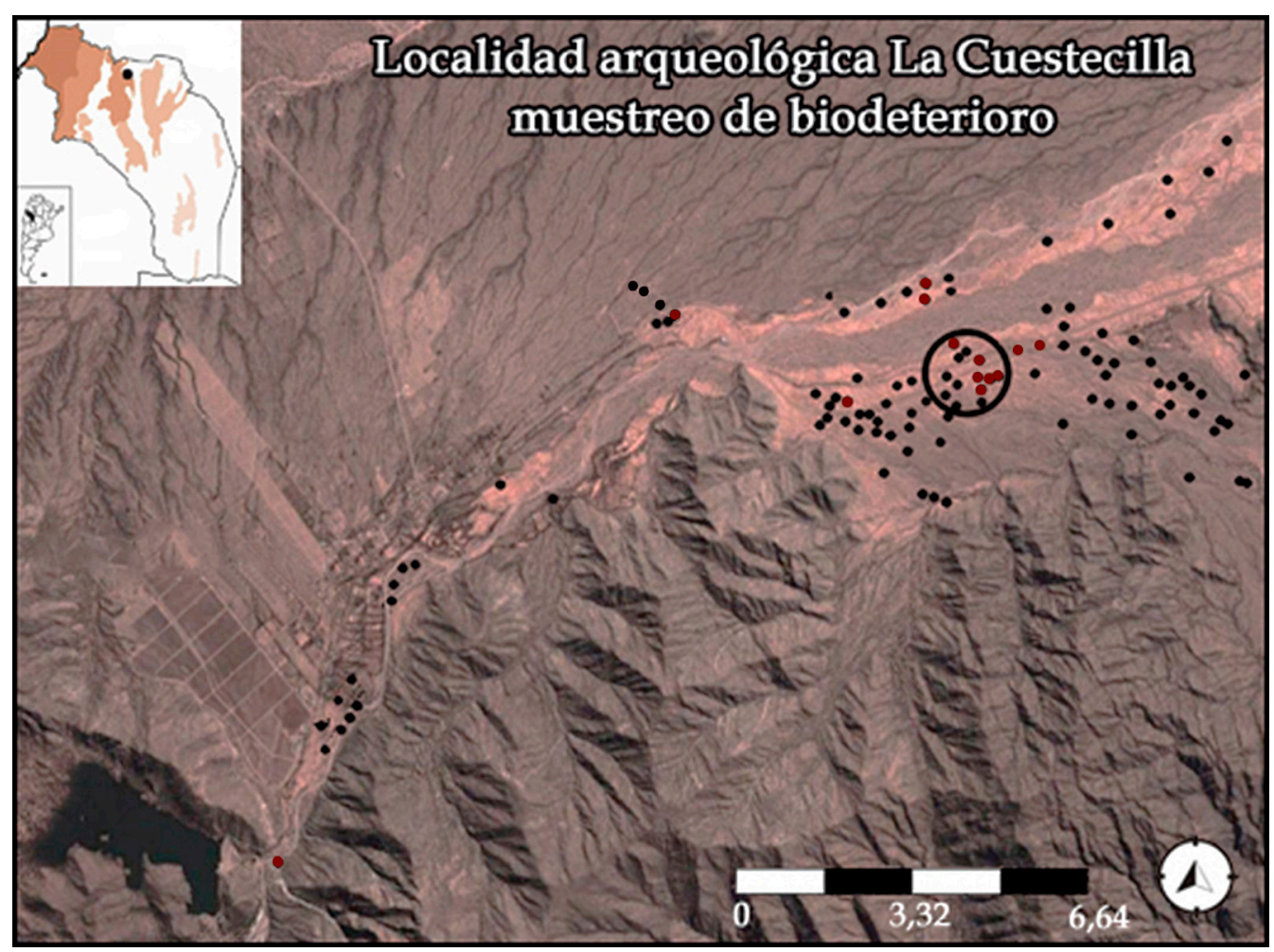

Figura 1. Ubicación geográfica del área de estudio. En color sitios muestreados. El círculo señala el sitio LC. 
Figura 2. Tipos morfológicos presentes en el área de estudio. Vasijas del Museo de Chañarmuyo:

a) Aguada pintada tricolor, jarra y puco).

b) Transición Ciénaga-Aguada (jarra) y Aguada gris liso (puco).

c) Ordinario, olla y jarra con rastros de hollín en su exterior.

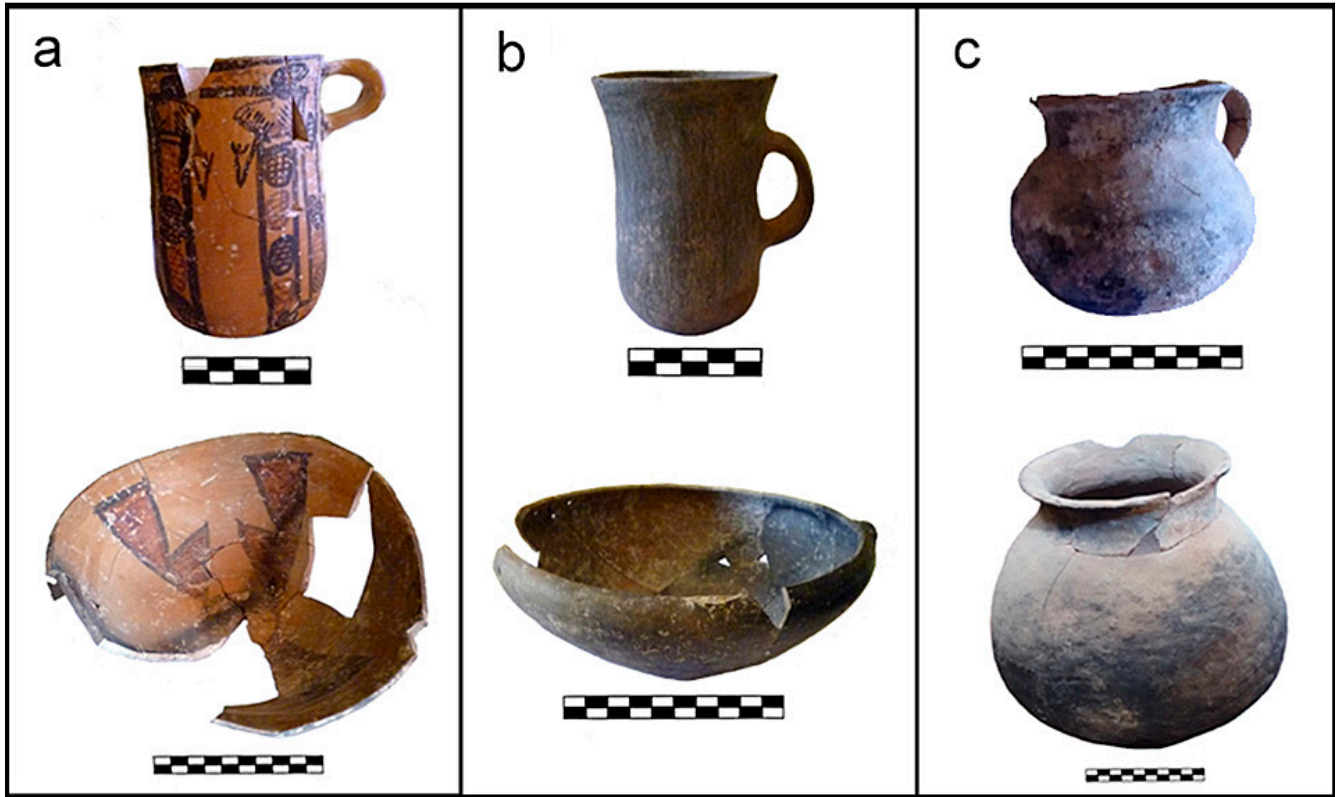

se analizaron materiales provenientes del valle como de la quebrada buscando diferencias y similitudes, tanto en el patrón de colonización como en su impacto en el material.

\section{Metodología}

Para analizar el biodeterioro en los tiestos cerámicos se siguieron tres pasos y, posteriormente, se ejecutó un cuarto para reconocer si los agentes microbiológcos eran propios de la biota local. El primero, involucró el trabajo interdisciplinar con liquenolos ${ }^{1}$ y microbiólogos ${ }^{2}$ para identificar, tipificar y clasificar los agentes microbiológicos, profundizar en su ecología y comprender su relación con la interfase cerámica mediante la aplicación de análisis de laboratorio y observaciones microscópicas.

Las identificaciones y tipificaciones de microorganismos se realizaron en el Laboratorio de Biodeterioro de Materiales del INIFTA (UNLP-CONICET, La Plata) por la Dra. Patricia Guiamet. Se emplearon métodos de cultivos tradicionales ${ }^{3}$ (YGC, PCA, BAT, Posgate B y CPS). Las colonias fúngicas se seleccionaron e identificaron por características morfológicas, mientras que las bacterianas se agruparon en primer lugar sobre la base del teñido por coloración Gram y en segundo por pruebas de identificación bioquímica (Guiamet et al., 2019). La identificación taxonómica de líquenes se realizó en dos etapas. La primera, en el INIBIOMA (Universidad de ComahueCONICET, Neuquén, Argentina) por el Dr. Alfredo Passo, buscó similitudes y diferencias mediante observaciones con lupa trinocula. La segunda, en el Herbario Hamburgense (Instituto de Plantas y Microbiología, Universidad de Hamburgo, Hamburgo, Alemania) por el Dr. Matthias Schultz, quién revisó las identificaciones previas y realizó nuevas a partir de la inspección de características relevantes mediante microscopio compuesto. Cuando necesario, las muestras se contrastaron con colecciones de referencia. El Dr. Schultz informó que la identificación taxonómica fue muy ardua, debido a que la mayoría de las especies pertenecía a la aún poco conocida clase Liquenomicetos (Schultz \& Büdel, 2002), situación complejizada por las escasas investigaciones para Sudamérica. En consecuencia, se basó en evaluar la incidencia de estos aspectos tecnológicos propios de proceso de manufactura en la colonización biológica. Asimismo, 
bibliografía de otras regiones.

Los análisis de laboratorio implicaron un ensayo de bioadherencia y formación de biofilm y un test de acidificación de la cerámica. Las microscopias se dividieron en ópticas (estéreomicroscopía binocular y trinocular) para analizar los líquenes y electrónica con alcances de resultados químicos (SEMEDS) para analizar, fundamentalmente, los microorganismos.

El segundo paso implicó el estudio de las propiedades físicas y tecno-morfológicas del material para buscar patrones tecnológicos que pudieran estar condicionando el biodeterioro. Se realizaron análisis petrográficos, estadísticos y observaciones con lupa binocular (Soto et al., 2017).

El tercer paso se enfocó en determinar los tipos de deterioro presentes y las alteraciones ocasionados por la actividad biológica tanto en las superficies externas como al interior de la pasta, a partir de una revisión crítica del conjunto de las técnicas analíticas aplicadas. Los resultados se correlacionaron con literatura de otros bienes culturales afectados por las mismas especies identificadas.

El cuarto paso, apuntado a indagar el origen de la colonización biológica de los materiales cerámicos y su contexto ambiental, se dividió en dos etapas. La primera, el muestreo justificado de distintos sustratos naturales (rocas silíceas y sedimentarias, sedimento, vegetación seca y costras biológicas - soil crust ${ }^{4}$ ) en los sitios arqueológicos del valle para proceder a la identificación taxonómica de líquenes y la tipificación de microrganismos en sedimento (ídem metodología aplicada a las cerámicas, con la salvedad del uso de un medio de cultivo adicional semejante a la cerámica). La segunda, la medición de variables ambientales como la temperatura (T), humedad relativa (HR), el punto de condensación del rocío (Pt rocío) en LC G9, in situ, mediante un termo higrómetro (H08-004-02) y el análisis de la composición química de sedimento de $30 \mathrm{~cm}$ de profundidad de Aldea 3 (Soto 2019).

Se empleó el concepto sustrato al hacer referencia al desarrollo y/o crecimiento de las especies en los ecosistemas naturales, mientras que el término material se aplicó cuando la colonización biológica ocurre en un bien cultural. La línea de estudios del biodeterioro en boga, desde las ciencias biológicas, no realiza dicha distinción (por ejemplo, Allsopp et al., 2004; St. Clark \& Seaward, 2004; Verran, 2013). No se empleó el concepto soporte en tanto la colonización biológica no fue producto de la decisión humana para comunicar algún mensaje social, simbólico o artístico.

\section{Resultados y discusión}

El muestreo sistemático estratificado reveló que el 50\% de la cerámica superficial se encontraba colonizada por líquenes, lo que significa que la mayoría de los materiales expuestos a la intemperie son afectados por este proceso, se encuentren en el valle o en las quebradas.

Se individualizaron diferentes especies de tres tipos de agentes microbiológicos: líquenes, bacterias y hongos filamentosos. Los líquenes son microorganismos complejos compuestos por una asociación simbiótica entre una parte fototrófica, algas verdes o cianobacterias, y otra fúngica (St. Clair \& Seaward, 2004). Los talos son las estructuras superiores que visualizamos sobre las cerámicas, encargadas de la fotosíntesis y la reproducción por medio de la liberación de esporas. Las hifas fúngicas se desarrollan al interior del material, no siendo visibles, y sintetizan nutrientes, asimilan los hidratos de carbono producidos en la fotosíntesis y producen compuestos que depositan en el talo para protegerlo de otros organismos (Kumar \& Kumar, 1999). Su lento crecimiento puede durar cientos de años, razón por la cual algunas especies son empleadas para la liquenometría como método de datación relativa.

Las bacterias son organismos unicelulares procariotas ( $\sin$ un núcleo definido) de formas bacilares o esféricas, algunas poseen flagelos, que pueden conformar filamentos, láminas y aglutinaciones. Se reproducen por división celular y la extracción de nutrientes al descomponer cualquier tipo de sustrato y/o material, por la segregación de sustancias poliméricas extracelulares (encimas y proteinas) - SPE. Se las encuentra en prácticamente todos los ambientes del planeta (Rose, 1981) y muchas de ellas pueden ser perjudiciales para la salud (Rutala \& Weber, 2017). Los hongos son organismos eucariotas unicelulares (levaduras) o filamentosos (antiguamente llamados mohs). Los hongos filamentosos fueron los identificados y se componen de hifas, filamentos que pueden unificarse conformando micelios y estructuras mayores con cuerpos fructuosos (ejemplo, portobello). Pueden reproducirse de forma sexual o asexual. Algunos son considerados plantas, parásitos o agentes patógenos. La mayoría vive en la materia orgánica, en tanto su nutriente fundamental es el carbono (Rose, 1981; Sterflinger, 2010).

Un tratamiento más sistemático de la taxonomía de líquenes permitió identificar ocho especies (Tabla 1) y precisar algunas de las primeras identificaciones que se habían mostrado dificultosas por carecer de colecciones de referencia (Soto, 2015). En todos los casos se trató de cianolíquenes crustosos, especies fuertemente adheridas al material y de imposible remoción, adaptadas a ambientes áridos cálidos y/o fríos y a sustratos rocosos ricos en sílice de diversas partes del mundo, desde el Desierto de Sonora en Estados Unidos hasta las planicies de Mongolia en China. En tanto muchas de estas especies son muy pequeñas, negruzcas, conspicuas y poco conocidas para la liquenología, su determinación tuvo que descansar en literatura de otras regiones (Büdel, 1987; Nash et al., 2002; Moreno \& Egea, 1992, entre otros). Algunas de las especies identificadas como Psorotichia sp.y otras Liquenomicetas se hallaban parasitadas por Zwackhiomyces sp., un género de hongo liquenoso que contribuyó a dificultar las identificaciones. Lichinella intermedia se destaca por exhibir una amplia dispersión mundial y por su adaptabilidad a sustratos rocosos como sedimentarios en zonas áridas (Schultz, 2009). La adaptación de los cianolíquenes a este tipo de ambientes donde predominan las intensas radiaciones solares puede inferirse macroscópicamente al contemplar la pigmentación obscura y/o amarronada de los talos (Mager \& Thomas, 2011; Pietrasiak et al., 2013), ya que el resto de los líquenes poseen coloraciones más claras. Si bien el cuarzo en tanto inclusión no suele presentar rasgos diagnósticos para los análisis tecnológicos, su abundancia en cerámicas arqueológicas (Cremonte \& Pereyra Domingorena, 2013) las asemeja a los sustratos rocosos silíceos dónde todas las especies de cianolíquenes identificadas crecen naturalmente (por ejemplo, areniscas y granitos). Lo que sugiere que estos agentes biológicos colonizan materiales con una composición mineralógica similar.

No se registraron diferencias significativas entre los agentes biológicos identificados en las cerámicas colectadas en la quebrada (PC) y los sitios del valle (Aldeas y sectores de LC), ya que todas las especies se registran en ambos ambientes. No obstante, en el valle predomina el desarrollo de los cianolíquenes, 
acorde a la baja vegetación y directa incidencia de la luz solar, en contraste con los tiestos colectados de las laderas de la quebrada donde prevalece una tupida vegetación. Mientras que en el PC se reconoció un desarrollo más intenso de la actividad microbiana al interior de la matriz cerámica con abundante presencia de SPE y estructuras fúngicas.

Observaciones por microscopía óptica demostraron la capacidad de los cianolíquenes de biomovilizar por medio de sus hifas (Figura 4a) los minerales de hasta $5 \mathrm{~mm}$ que forman parte de las inclusiones propias de la pasta, absorbiéndolos e integrándolos a los talos (Figura 4b) (Ascaso et al., 2002; De los ríos et al., 2009;
St. Clair \& Seaward, 2004). Se observa un efecto conjunto entre la meteorización, degradación de material por procesos físicos y químico in situ, los agentes postdepositacionales (sensu Schiffer, 1987) que van deteriorando las superficies externas de las cerámicas y fracturando los tiestos, y la colonización de los cianolíquenes en áreas debilitadas del material: microfisuras (Figura 5a, $5 \mathrm{c}$ ), oquedades (Figura 3g), cantos (Figura 3) e irregularidades de las superficies (Figura 3a, 3c, 3i, 3g, 5b). El desgranado de la cerámica se visualiza como un polvo blancuzco en torno a las microfisuras (Figura 3c) o talos (Figura 3d, 3h, 3i). También se visualizaron biopits (Ascaso et al., 2002) circulares producto de

\begin{tabular}{|c|c|c|c|c|}
\hline \multirow{2}{*}{$\begin{array}{l}\text { AGENTES } \\
\text { MICRO- } \\
\text { BIOLÓGICOS }\end{array}$} & \multirow{2}{*}{ ESPECIES IDENTIFICADAS } & \multicolumn{2}{|c|}{ ESTILOS CERÁMICOS } & \multirow{2}{*}{$\begin{array}{c}\text { DATOS } \\
\text { COMPARATIVOS }\end{array}$} \\
\hline & & Aguada & Ordinario & \\
\hline \multirow{8}{*}{$\begin{array}{l}\text { CIANO- } \\
\text { LIQUENES }\end{array}$} & $\begin{array}{l}\text { Lichinella intermedia (Henssen, } \\
\text { Büdel \& T.H. Nash) }\end{array}$ & $\mathrm{X}$ & $\mathrm{X}$ & Rocas silíceas, sedimento \\
\hline & $\begin{array}{l}\text { Lichinella mongolica ined. (H. } \\
\text { Magn) }\end{array}$ & $\mathrm{X}$ & $\mathrm{X}$ & Rocas silíceas, sedimento \\
\hline & Peccania sinaiensis ined. (Vain) & $\mathrm{X}$ & & Sedimento \\
\hline & $\begin{array}{l}\text { Peltula obscurans var. } \\
\text { Deserticola (Zahlbr., Wetmore) }\end{array}$ & $\mathrm{X}$ & & Rocas \\
\hline & $\begin{array}{l}\text { Peltula obscurans var. Hassei } \\
\text { (Zahlbr., Wetmore) }\end{array}$ & $\mathrm{X}$ & & Rocas silíceas, sedimento \\
\hline & $\begin{array}{l}\text { Peltula omphaliza (Nyl., } \\
\text { Wetmore) }\end{array}$ & $\mathrm{X}$ & & Rocas \\
\hline & $\begin{array}{l}\text { Psorotichia cf. montinii (A. } \\
\text { Massal., Forssell) }\end{array}$ & $\mathrm{X}$ & & Rocas \\
\hline & Psorotichia spec. & $\mathrm{X}$ & & Sedimento \\
\hline $\begin{array}{c}\text { HONGO- } \\
\text { LIQUENOSO }\end{array}$ & Zwackhiomyces spec. & & & Psorotichia spec. \\
\hline \multirow{4}{*}{ HONGOS } & Cladosporium spp. (Link) & $\mathrm{X}$ & $\mathrm{X}$ & $\begin{array}{l}\text { Ambientes de archivo, } \\
\text { textiles arqueológicos. }\end{array}$ \\
\hline & Curvularia spp. (Boedijn) & $\mathrm{X}$ & $\mathrm{X}$ & Ambientes de archivo \\
\hline & $\begin{array}{l}\text { Apergillus niger (van } \\
\text { Tieghem) }\end{array}$ & $\mathrm{X}$ & $\mathrm{X}$ & $\begin{array}{l}\text { Ambientes de archivo, } \\
\text { documentos y fotografías. }\end{array}$ \\
\hline & Penicillium spp. (Link) & $\mathrm{X}$ & $\mathrm{X}$ & $\begin{array}{l}\text { Ambiente de archivos, } \\
\text { documentos y fotografías, } \\
\text { textiles arqueológicos. }\end{array}$ \\
\hline \multirow[t]{2}{*}{ BACTERIAS } & Bacillus sp. Cohn) & $\mathrm{X}$ & $\mathrm{X}$ & $\begin{array}{l}\text { Areniscas, ambientes de } \\
\text { archivo, documentos y } \\
\text { fotografias, cerámicas y } \\
\text { monumentos de piedra } \\
\text { arqueológicos. }\end{array}$ \\
\hline & $\begin{array}{l}\text { Pseudomonas aeruginosa } \\
\text { Schroeter, Migula) }\end{array}$ & & $\mathrm{X}$ & $\begin{array}{l}\text { Textiles arqueológicos, } \\
\text { metales industriales, } \\
\text { humanos, animales. }\end{array}$ \\
\hline
\end{tabular}

Tabla1. Lista de agentes microbiológicos identificados en las cerámicas. Datos comparativos de otros substratos y materiales donde también se han identificado (se mencionan entre paréntesis los especialistas que identificaron las especies y géneros). 


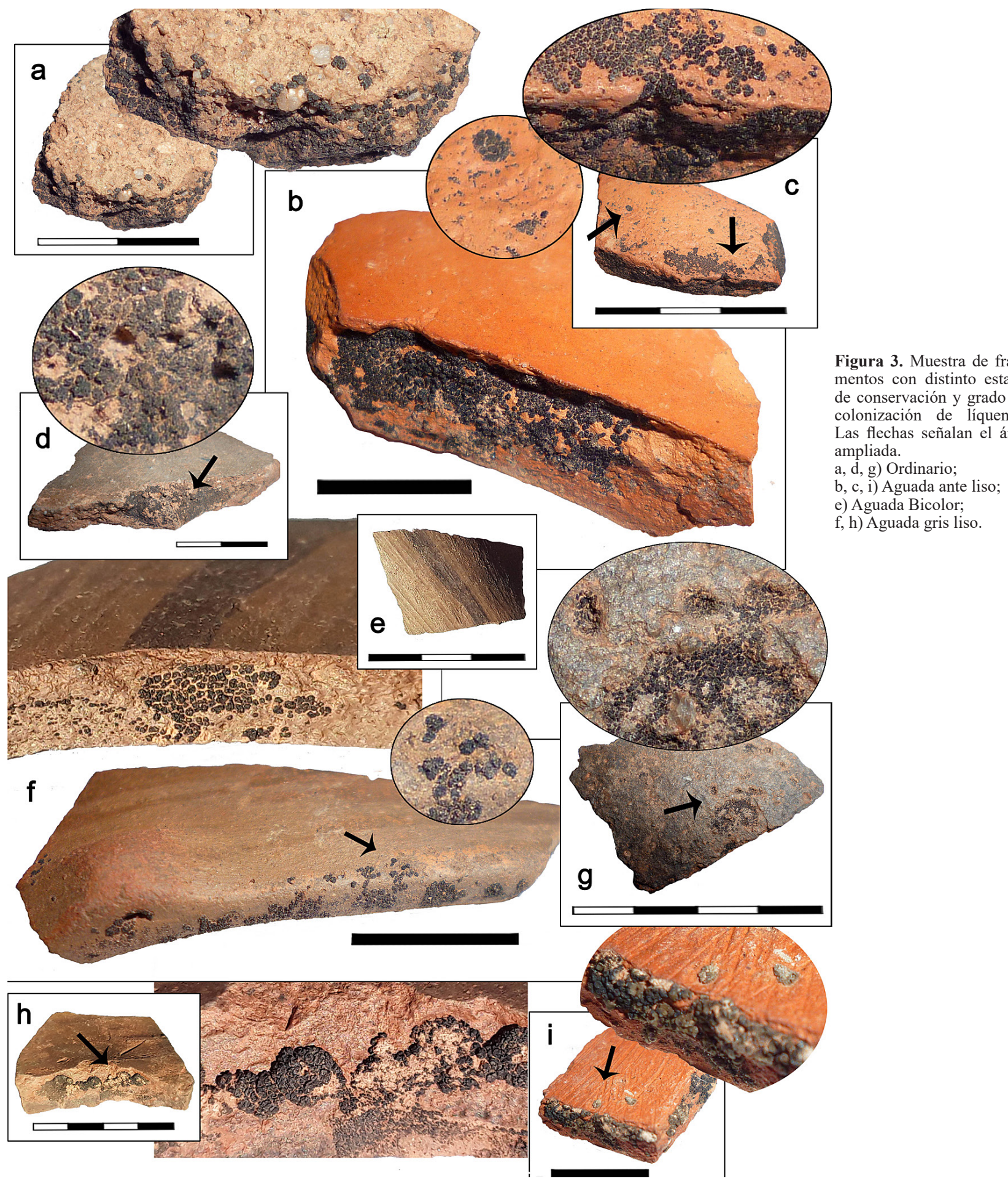

talos desprendidos de entre 0,5 a $1,5 \mathrm{~mm}$ y el desgranado de la cerámica en las inmediaciones a estos (Figura 3d). Los biopits reconocidos poseen contorno circular regular debido a que la forma de crecimiento de los talos es radial desde un epicentro, si bien en su extremo superior puede variar su morfología. En cambio, las oquedades producto de procesos erosivos, por ejemplo el picado de la arena, o agentes postdepositacionales como el pisoteo por animales, no suelen corresponderse con geometrías regulares.

Las observaciones por SEM, en el caso de los cianolíque- nes, permitieron corroborar el patrón de colonización de las áreas debilitadas de los materiales cerámicos. La mayor resolución favoreció la apreciación de la pulverización de la matriz por el desarrollo de los talos, los biopits dejados por su desprendimiento (Figura 6b) y la perforación de sus hifas (Figura 6d). Asimismo, se visualizó en detalle como microfisuras de escasos micrones surgían a partir de los talos (6b) o entorno a aquellos en estado de deshidratación (6c), en cuyo caso, se mostraban pronunciadas y formando un entramado en torno a los mismos. También se 

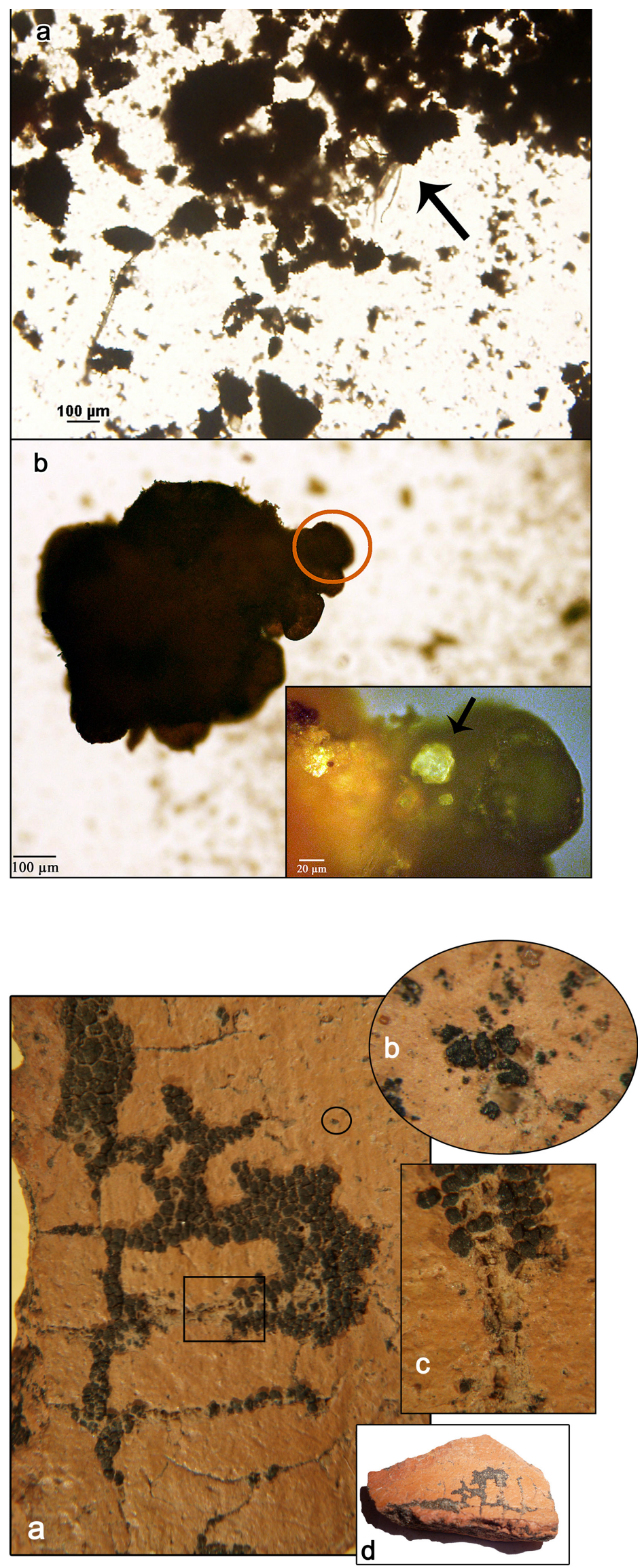

Figura 4. Tiesto Ag. ante - cianoliquen, con lupa binocular. (a) Hifas al interior de la pasta. (b) Talo con magnificación de la apotecia (círculo), se observan inclusiones minerales incorporadas a la estructura (flecha).

constató la relación simbiótica entre éstos organismos con hongos y bacterias que crecen sobre sus mismas estructuras biológicas (Guiamet et al. 2019).

En el caso de los microorganismos, el SEM demostró que las bacterias desarrollan bajo relieve en las superficies (Figura 7d), al interior de los poros de la cerámica o de los biopits ocasionados por los cianolíquenes tanto en superficies externas o en la pasta, estos últimos producto de las perforaciones ocasionadas por sus hifas y no por el desprendimiento de sus talos (Guiamet et al., 2019; Soto, 2019). A la par, se visualizó SPE generada por la actividad microbiana recubriendo la pasta, lo que imposibilitó apreciar los cristales de las arcillas o las inclusiones minerales presentes (Figura 7a, 7b, 7c). Estas sustancias funcionan al mismo tiempo como adhesivo para el material suelto desprendido por la pulverización del sustrato por los líquenes (Figura 6d) o recibido del medio cuando se trata de superficies externas (Figura 7c, 7d) (Gorbushina, 2007; Gorbushina \& Broughton, 2009). La producción de ciertos ácidos que disuelven el material y dejan una huella de diminutas cavidades de $c a .1$ a $7 \mu \mathrm{m}$ fue evidenciada (6c). Un ensayo de acidificación en los tiestos señaló la disminución de dos líneas de $\mathrm{pH}$ en tan sólo 15 días (Soto, 2019), concordante con la producción de metabolitos ácidos por hongos del género Aspergillus y Cladosporium en ladrillos de adobe histórico en Brasil por Fazio et al. (2015); especies presentes en las muestras. El estrés de la fábrica cerámica también es consecuencia de las hifas fúngicas que atraviesan la matriz (Sterflinger, 2010) (Figura 7c) y crecen en microfisuras separando el material, como de la intensa actividad microbiológica que genera el agrietamiento del sustrato, visible en sectores con sólo SPE (Figura 7b) o con también presencia de bacterias creciendo bajorelieve (Figura 7d).

Mediciones elementales por EDS confirman que en los sectores con actividad biológica se incrementan los valores de carbono y oxígeno, probablemente por la descomposición del sílice al segregarse ácido 2-keroglutoso por Bacillus sp. (Papida et al., 2000; Rose, 1981; Warscheid \& Braams, 2000) o la liberación de moléculas de carbono de magnesio por otro tipo de bacterias que no llegaron a tipificarse (Gutarowska et al. 2015). La presencia de elementos como el calcio puede asociarse a la producción de oxalatos de calcio por cianolíquenes al igual que su biomoviliación (Ascaso et al., 2002; St. Clair \& Seaward, 2004). Sin embargo, el reconocimiento de elementos inusuales en

Figura 5. Tiesto Aguada ante de LC con lupa trinocular. a) 10x cianolíquenes desarrollando en las áreas debilitadas de la cerámica, grietas y microfisuras y en las irregularidades de las superficies. b) x56, ampliación área circulada "a", se observan los talos en la superficie. c) x56, magnificación sector rectangular "a", nótense cómo los cianolíquenes desgranan la cerámica. Se observa cerámica pulverizada suelto en la grieta y en torno a los talos. 
la pasta también puede ser resultado de la actividad biológica. A modo de ejemplo, Gorbushina et al. (2001) ha observado que ciertas especies de líquenes son capaces de sintetizar cristales de ópalo y fosforita en sustratos rocosos de Venezuela. También se observó la producción de pigmentación celeste-grisácea por hifas fúngicas creciendo sobre cianolíquenes (Soto, 2019). Los cambios cromáticos producidos por pigmentos biogénicos han sido reconocidos en arquitectura y variedad de materiales artísticos (De los Ríos et al., 2009; Guiamet et al., 2008; Verrán, 2013; Valgañón, 2008).

Con el fin de evaluar la posibilidad de que elecciones en el proceso de manufactura o la conjunción de rasgos que hacen a los estilos cerámicos estuviesen condicionando y/o determinando la colonización biológica, se analizaron las variables: tratamiento de superficie (pulido y alisado), decoración (pintada, grabada e incisa), textura de la pasta (compacta, semi-compacta y deleznable) y estilos. Los resultados indican que las variables antrópicas analizadas no son significativas para la colonización de agentes biológicos (Soto et al., 2017). Si bien los tiestos Ordinarios presentan superficies rústicas que exhiben más irregularidades dónde los cianolíquenes pueden adherirse con mayor facilidad, los fragmentos Aguada de pastas compactas y usualmente acabado pulido, también se encontraban intensamente colonizados. Las únicas variables tecnológicas con cierta incidencia en el proceso, serían aquellas que constituyen elecciones del proceso de producción que afectan las propiedades físicas del producto final (por ejemplo, uso de antiplásticos, grado de homogenización de la pasta, atmósfera de cocción y temperaturas de cocción), como porosidad y resistencia. La porosidad del material es una característica que se comparte con adobes históricos (Fazio et

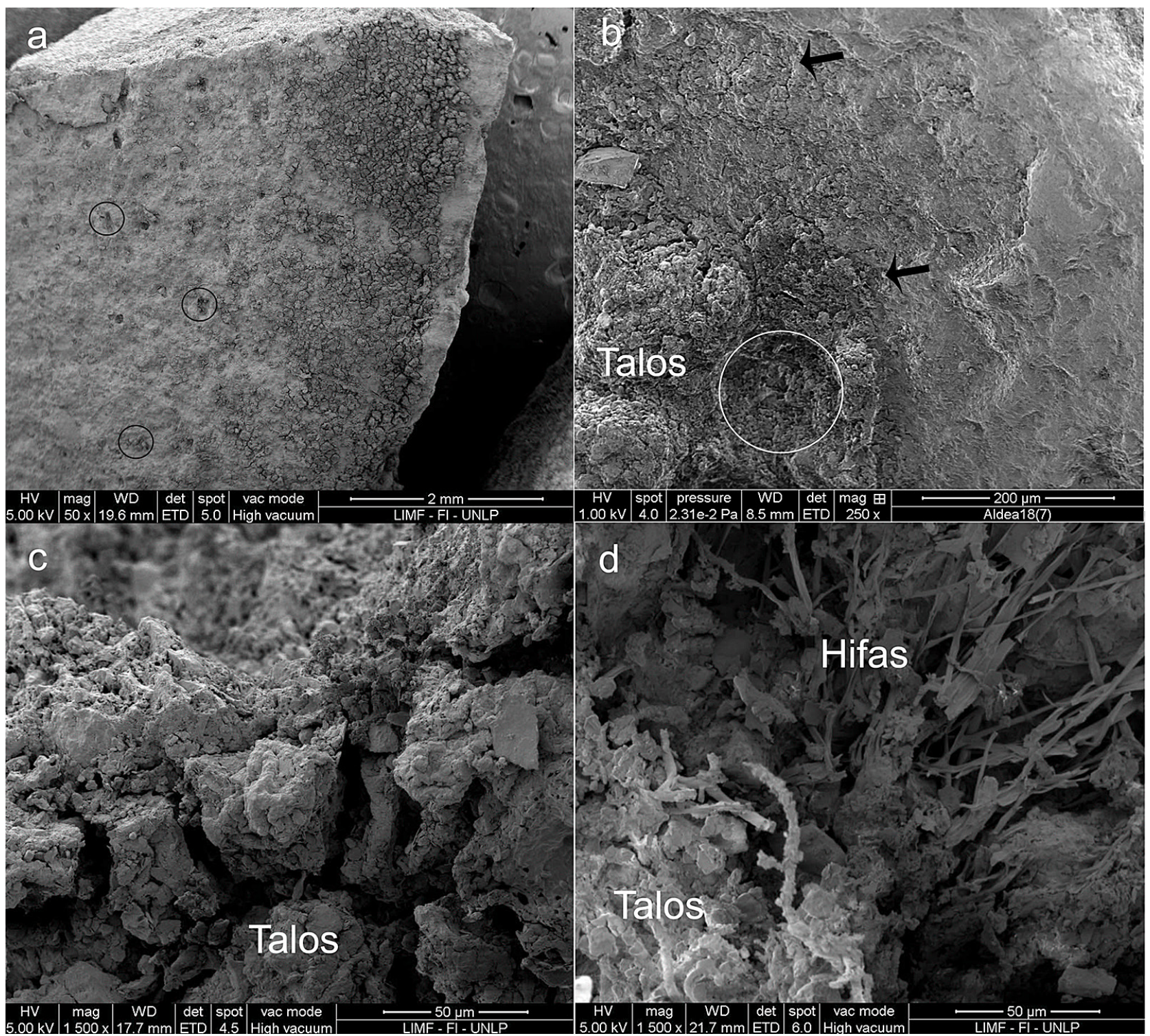

Figura 6. SEM cianolíquenes en tiestos LC. a) Canto Ordinario 50x, los círculos señalan biopits producidos por talos desprendidos, algunos ya poseen nuevos líquenes desarrollando. b) Superficie externa Aguada ante 250x, se observa hacia la izquierda el desgranado de la cerámica y las subsecuentes microfisuras en torno a los talos (flechas). El círculo indica un biopit producto de un talo desprendido. c) Superficie externa Ordinario 1500x, detalle de sector con talos deshidratados. Obsérvese las notorias grietas que los circunscriben y los micropits en el sector superior (puntos negros), probablemente consecuencia de la producción de metabolitos ácidos. d) Canto Aguada ante 1500x, magnificación de sector con desgranado por la acción de hifas, las cuales se adentran en la matriz a la vez que actúan como adhesivo de material suelto. 
al., 2015), recubrimientos de mortero (Ariño \& Saiz-Jimenez, 2004) o sustratos rocosos donde algunas de estas especies ya han sido identificadas. En el caso de los morteros y el adobe, su baja resistencia y alta permeabilidad, los convierte en materiales más lábiles y susceptibles al deterioro mecánico por líquenes. La incidencia de la porosidad en este proceso se corroboró con los cultivos microbiológicos en laboratorio, puesto que las muestras Aguada de pastas más compactas y menos porosas presentaron menos recuentos de bacterias que las muestras Ordinarias, de pastas semi-compactas y mayor porosidad (Guiamet et al., 2019; Soto, 2019). Concordante, a su vez, con observaciones de microorganismos desarrollándose en microcavidades del monasterio de Jerónimo en Lisboa (Ascaso et al., 2002) o de las Iglesias romanescas de Segovia (De los Ríos et al., 2009).

Para tener una primera aproximación a como los agentes microbiológicos incrementan la porosidad de las pasta, se realizaron mediciones a través de diversas microscopías. Microscopio petrográfico para los poros de la matriz. Lupa binocular para el picado por erosión, meteorización y/o pisoteo de animales y los biopits producidos por cianolíquenes en superficies externas. SEM para biopits internos asociados a actividad biológica (Figura 8) (Soto, 2019). Efectivamente, se da una sinergia entre la meteorización, la erosión, los procesos postdepositacionales y las propiedades físicas de la cerámica que potencian la colonización biológica a la vez que debilitan la fábrica del material.

Una recapitulación de los resultados expuestos permite afirmar que los tres tipos de biodeterioro se encuentran presentes en los materiales cerámicos y que el daño ocasionado por líquenes es el de mayor gravedad (Seaward, 2003; St. Clair \& Seward, 2004). El deterioro mecánico se manifiesta por la acción perforadora de las hifas (Figura 6d, 7c), la biomovilización de minerales por cianolíquenes (Figura 4b), el agrietamiento del material (Figura 5a, 5c, 6b, 6c, 7d) y la pulverización de la matriz cerámica (Figura 4c, 6b, 6b) por la acción conjunta de los

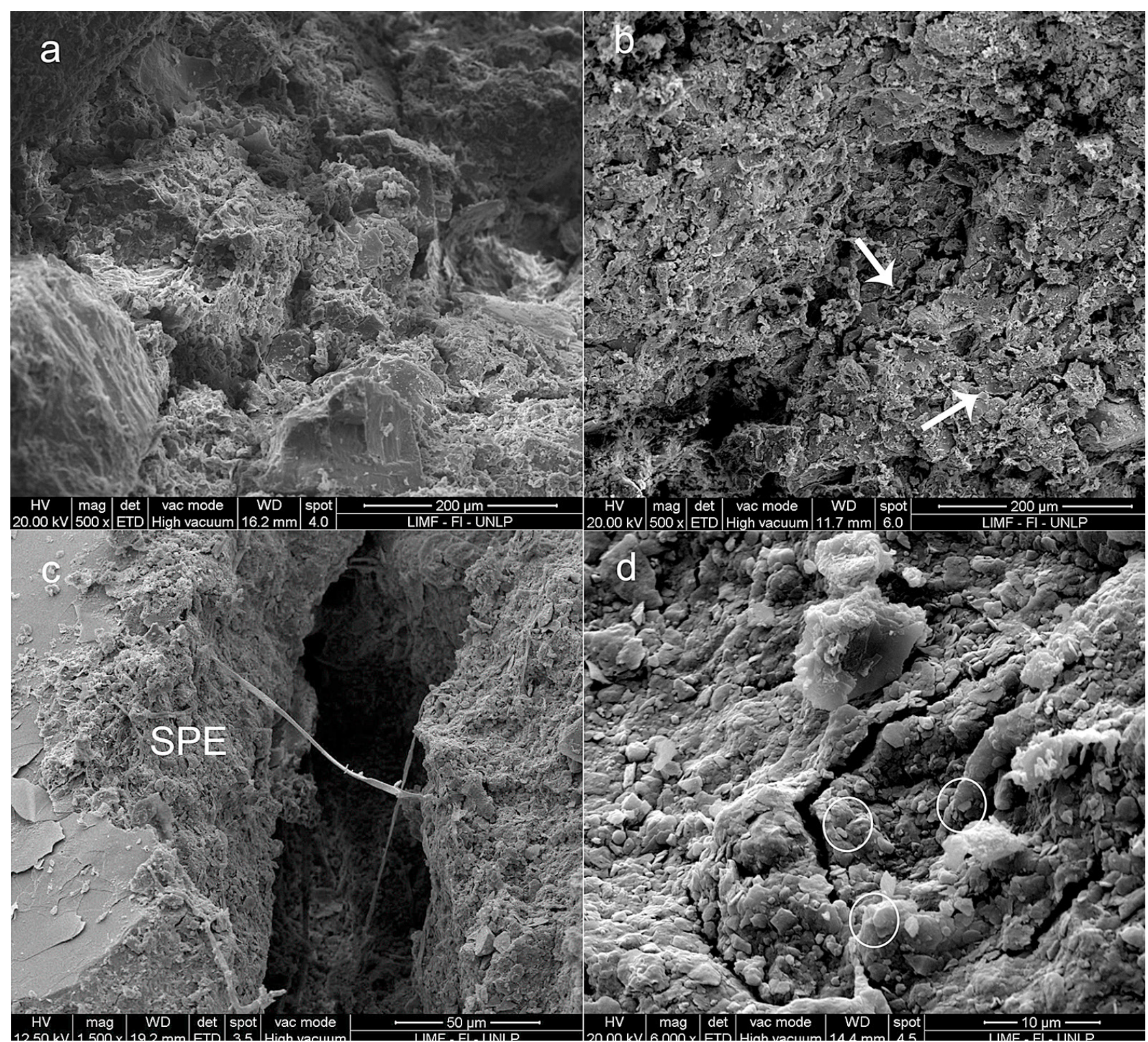

Figura 7. SEM - SPE recubriendo la matriz. a) Ordinario PC 500x, SPE recubriendo el interior de la pasta. b) Aguada gris LC 1500x, se observan microgrietas (flechas) y presencia de SPE al interior de la pasta. c) Ordinario LC 1500x, grieta en la superficie externa que muestra intensa actividad microbiana al interior de la pasta: producción de SPE y desarrollo de hifas fúngicas. d) Ordinario LC 6000x superficie externa, se visualizan microfisuras y SPE que opera como adhesivo del material desgranado. Los círculos indican bacterias creciendo bajorelieve. 


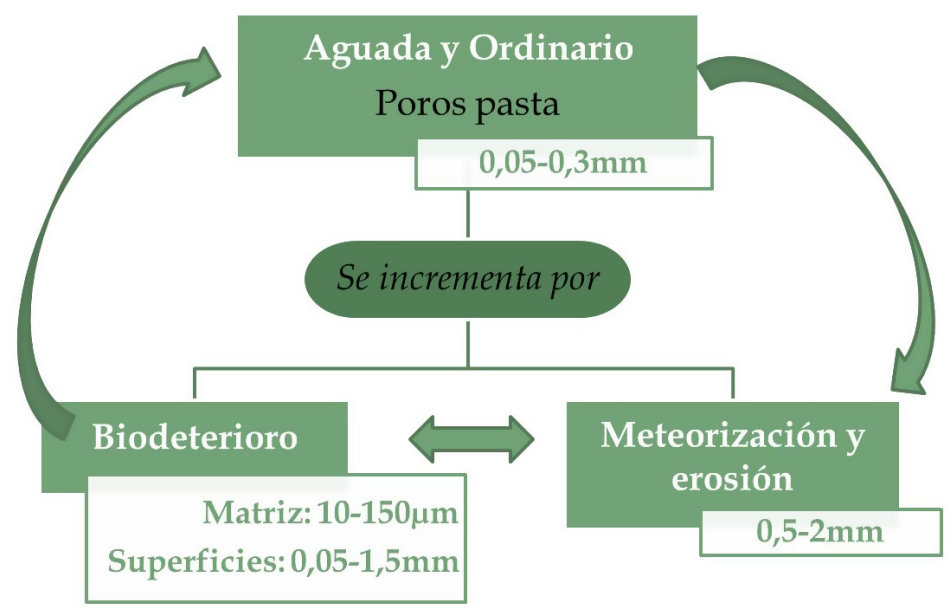

Figura 8. Gráfico de síntesis de sinergia de agentes involucrados en el biodeterioro de la cerámica arqueológica (Soto 2019).

agentes microbiológicos. El impacto bioquímico se observa por la producción de nuevos compuestos y elementos, la segregación de SPE (Figura 7a, 7b, 7c) y de metabolitos ácidos que alteran el $\mathrm{pH}$ y disuelven la pasta (Figura 6c). El daño estético se visualiza macroscópicamente en las costras de cianolíquenes (Figura 3) y la pigmentación producida por hongos filamentosos sobre líquenes en las superficies externas. Todas estas alteraciones y deterioros se registraron en un ambiental hostil para los agentes microbiológicos, ello significa, que aun así los materiales cerámicos arqueológicos son bioreceptivos (Guillite, 1995).

Respecto al análisis del ambiente, la identificación taxonómica de líquenes y el aislamiento y tipificación de microorganismos de sedimento, confirmó la presencia de especies reconocidas en las cerámicas (Tabla 1). Las cianolíquenes presentaron tres de las especies más abundantes en los tiestos, $L$. intermedia, $L$. mongólica ined. y Peltula obscurans var. Hassei, aseverando su gran capacidad adaptativa a sustratos naturales y materiales de composición mineralógica similar. Los resultados de la composición química del suelo demostraron que los nutrientes presentes son escasos para el desarrollo de plantas superiores, pero suficientes para los microorganismos (Rose, 1981). Coincidente con la vegetación actual de plantas xerófilas, arbustos espinosos y cactáceos (Cabrera, 1976). El patrón se repite, se trata de organismos adaptados a climas áridos que forman parte de la biota local, lo que indica que el deterioro por agentes biológicos es parte de los procesos naturales de degradación de materiales cerámicos endémicos a este tipo de ambientes. La adaptabilidad de estas especies a condiciones asiduas de hostilidad ambiental se confirmó, a su vez, con las mediciones de T, HR y Pt de rocío del área de estudio. En líneas generales, la amplitud térmica diaria llegó a alcanzar hasta $30^{\circ} \mathrm{C}$ y estar asociada a cambios más bruscos en la HR que alcanzaron 43 unidades de diferencia. Ello permitió calcular el Pt de rocío de $0,6^{\circ} \mathrm{C}$ a las 2 am y $12,6^{\circ} \mathrm{C}$ a las $11 \mathrm{am}$. En zonas desérticas y ambientes áridos, la biota adquiere la humedad necesaria durante las horas nocturnas, situación que se prolonga hasta las últimas horas de la mañana en los valles de altura y sectores montañosos como el área de estudio, momento en que el sol se llega a elevarse por sobre los cerros (Soto, 2019).

Aunque los agentes microbiológicos no posean la capacidad de movilizar fragmentos como las lombrices o pequeños insectos que participan activamente en los procesos de pedogenesis (Wood \& Johnson, 1978; Zarate et al., 2000-2002), están contribuyendo con el resto de factores postdepositacionales a la dinámica de suelos en ambientes áridos y al deterioro de los materiales en superficie. Es importante tener presente que aquellos materiales cerámicos en estratigrafía también pudieron haberse visto expuestos a la colonización por líquenes antes de ser incorporados al contexto arqueológico, ergo, no necesariamente presentaran condiciones óptimas de conservación en contraposición a aquellos superficiales. Asimismo, aquellos no impactados por líquenes pueden ser colonizados por microorganismos presentes en el sedimento.

\section{Impacto del biodeterioro}

A partir de una lectura crítica de los resultados, se desprenden tres cuestiones relevantes directamente vinculadas a los agentes microbiológicos colonizando materiales cerámicos arqueológicos: riesgos para la preservación del material, riesgos para la salud de investigadores y personal técnico destinado al manejo de colecciones e implicancias para la preparación de muestras y análisis de datos arqueométricos. Las dos primeras son cuestiones que se explicitan en sí mismas, la última, por el contrario, requiere de un mínimo desarrollo para ponerse en evidencia.

\section{Riesgos para la preservación}

El biodeterioro producido por líquenes posee serias connotaciones para la conservación de cerámica arqueológica. Ya en la década de los ochenta el liquenólogo Mark Seaward había advertido que el daño mecánico por descamación de superficies producido por líquenes en vasijas romanas de gran porte, se producía en un plazo relativamente corto, 15 años, en comparación con los procesos naturales de biodegradación de rocas (Seaward, 1988). El problema, concretamente, es que los cianolíquenes son muy difíciles de remover en su totalidad debido a que las hifas fúngicas desarrollan al interior del material y a partir de ellas pueden volver a crecer los talos; al igual que un árbol puede volver a crecer si sus raíces son fuertes. Varias investigaciones han demostrado que la aplicación de tratamientos con biocidas en sitios patrimoniales no es un método eficiente de control de los agentes biológicos porque estos vuelven a reincidir con mayor intensidad (St. Clair \& Seaward, 2004; Kakakhela et al., 2019). El daño de la comunidad biológica original termina posibilitando la colonización por nuevas especies, a veces más perjudiciales que las primeras, complejizando el proceso y 
causando un impacto mayor.

La importancia de conocer todos los agentes que participaron en los procesos formadores de sitios arqueológicos, en el soterramiento de materiales como durante su turbación, también implica la identificación de agentes microbiológicos. Hongos y bacterias en la matriz sedimentaria pueden trasladarse al material y reactivarse cuando varían las condiciones ambientales del área de depósito, ocasionando un severo deterioro. Esto puede pasar transcurridos seis meses (Coutinho et al., 2016), un año (Gromaire et al., 2015) o más tiempo (Colonna-Preti \& Eeckhout, 2014). Además, la resistencia a condiciones ambientales adversas de los agentes biológicos reconocidos en este estudio, demuestra que la mera regulación de los factores indirectos de deterioro por la conservación preventiva no es un método eficiente (Soto \& Guiamet, 2017). Un ejemplo concreto es el caso de ColonnaPreti y Eeckhout (2014), dónde los primeros tratamientos para lidiar con el biodeterioro en el material cerámico realizados en el 2008, desalinización de las piezas y limpieza con etanol, no fueron eficaces, extendiéndose la contaminación a piezas cercanas. En el 2009 se procedió a la identificación de las especies, revelando que se trataba únicamente de bacterias del orden de los antinomicetos, entre las que se encontraba el género Bacillus reconocido en esta investigación. A partir de ese punto se pudo avanzar en experimentaciones orientadas a determinar el biocida adecuado, el cual se aplicó en dos años consecutivos tras un nuevo proceso de limpieza y desalinización.

Es primordial conocer con qué agentes microbiológicos estamos tratando antes de aplicar métodos de limpieza y control inadecuados que podrían llegar a generar repercusiones indeseadas en el material. Asumir que el simple acondicionamiento de las guardas o control de las variables ambientales es suficiente para evitar la aparición de mohos y bacterias (Michalski, 2006; Strang \& Kigawa, 2009) es un error frecuente, en especial en casos dónde el biodeterioro proviene de los sitios arqueológicos.

Es de destacar que la presente investigaciones se desarrolló en el transcurso de cuatro años, periodo en el que las cerámicas analizadas siguieron demostrando la capacidad deterioradora de sus agentes biológicos, aunque los cianolíquenes entraron en decadencia al estar en guardas herméticas sin exposición a la luz solar y humedad ambiental, no lo hicieron los otros microorganismos (Soto, 2019).

Para preservar el patrimonio arqueológico existen una serie de pasos básicos que no pueden ser salteados. De forma diferente pero similar, el ejemplo citado nos remite a los antiguos casos de remontajes de piezas dónde no se contemplaba los componentes originales de los materiales ni su compatibilidad, buscando un simple fin estético. A pesar de carecer de recursos, se pueden tomar las precauciones necesarias para el manejo de los materiales y su guarda si se es consciente de la posibilidad de que existan agentes microbiológicos en los materiales porque, simplemente, conformaban la biota de los sitios arqueológicos (Soto \& Guiamet, 2017). Una posible solución es el dictado de cursos y seminarios sobre estas problemáticas estrechamente vinculados al patrimonio cultural. Otra, es la contemplación del biodeterioro en la formación de grado de futuros arqueólogos.

\section{Riesgos para la salud}

Los problemas de salud vinculados a la patogenisidad en objetos culturales han sido poco estudiados (Guild \& Mac Donald, 2004; Vaillant Callol, 2013), si bien gran cantidad de trabajos sobre la temática se abocan a material de archivos o bibliotecas tradicionales (documentos cuyo soporte es el papel o sus derivados) (Gutarowska, 2016; Lavin et al., 2014; Vaillant Callol, 2013). Desde las ciencias de la salud existen estrategias que apuntan a la desinfección de instrumental quirúrgico o espacios de trabajo (Rutala \& Weber, 2017), pero su aplicabilidad y efectividad no ha sido evaluada para bienes culturales.

Los microorganismos con rasgos patógenos se definen por la especificidad de la afección que provocan. La infección de un individuo por un patógeno no implica necesariamente que este enfermo, depende de su sistema inmunológico y de la presencia de afecciones particulares que lo tornen susceptible (Guild \& Mac Donald, 2004; Vaillant Callol, 2013). El riesgo de infección se torna mayor cuando se incrementa la contaminación del medio o cuando hay factores ambientales inadecuados (elevados valores de gases nocivos, bajos porcentajes de oxígeno o polvos y silicatos en suspensión).

Si nos remitimos a algunas de las especies identificadas en las cerámicas, tenemos al menos tres casos de agentes patógenos. Entre los hongos A. niger y Penicillium sp. son responsables de alergias y problemas respiratorios (Pattron, 2006; Lavin et al., 2014). Sin embargo, el riesgo mayor lo presenta la bacteria $P$. aeruginosa, uno de los más peligrosos agentes patógenos existentes debido a su resistencia intrínseca a los antibióticos (Luján Roca, 2014). Esta bacteria puede ocasionar infecciones externas en la piel y en los párpados de tratamiento tópico, hasta severas neumonías y hemorragias internas con elevada tasa de mortalidad. Estas especies nocivas han sido ampliamente estudiadas por la medicina humana y las ciencias de la salud, existiendo numerosas investigaciones sobre esterilización de materiales quirúrgicos para disminuir riesgos de contagio (Rutala \& Weber, 2017), pero poco se sabe cómo desinfectar bienes culturales contaminados por ellas (Pietrzak et al., 2017; Rajkowska et al., 2020).

La importancia y necesidad de tomar las mínimas precauciones cuando manipulamos bienes arqueológicos que no sabemos si están contaminados por algún agente patógeno, se ve destacada. El riesgo para la salud en la manipulación de los tiestos cerámicos del área de estudio es elevado sólo por la presencia de $P$. aeruginosa y, eso que no todos los microorganismos presentes pudieron ser identificados durante el desarrollo de la tesis ${ }^{5}$. Por ello, es fundamental el uso de protecciones para disminuir de los riesgos de contagio (guantes, delantales o batas de laboratorio). Sea por manipulación de materiales potencialmente contaminados o por encontrarse en un espacio de trabajo no acondicionado que podría estar acumulando microorganismos infecciosos (Guild \& Mac Donald, 2004; Strang \& Kigawa, 2009). La falta de presupuesto es clave en estas cuestiones, pero nuevamente, la falta de concientización del riesgo por parte de los investigadores y las autoridades institucionales es el aspecto central (John et al., 2016) que se traslada en la carencia de protocolos más adecuados o específicos para los diferentes casos (Kang et al., 2017) y de una política cultural clara.

\section{Implicancias para análisis arqueométricos}

El biodeterioro mecánico destruye y altera la pasta cerámica. Ello significa que al menos el primer centímetro, lo que en muchos casos puede exceder el grosor total de la vasija, se ve severamente perforado por las hifas de cianolíquenes y hongos filamentosos. Las hifas de cianolíquenes biomovilizan minera- 
les de hasta $5 \mathrm{~mm}$, lo que podría afectar la orientación de las inclusiones que indican tratamiento de superficies por pulido, la aplicación de engobe u/o el reconocimiento de la técnica de manufactura. En otras palabras, los análisis petrográficos de materiales cerámicos superficiales pueden verse sesgados. El reconocimiento de tratamientos de superficie e identificación de recetas de pigmentos y métodos de aplicación, también se vería impactado tanto por el daño mecánico porque si los fragmentos se encuentran intensamente colonizados por líquenes o con bacterias subsuperficiales, estos agentes pueden contribuir a la descamación de pinturas pos-cocción o el agrietamiento del engobe, efectos usualmente atribuidos a las tasas de contracción entre el cuerpo de la vasija y la solución coloidal arcillosa que sirve de base al engobe o a la mezcla pigmentaria (Acevedo et al., 2015; De la Fuente \& Pérez Martínez, 2008, entre otros).

Si bien el deterioro mecánico debe ser muy severo para afectar la totalidad de la pieza o el área a ser analizada, aun cuando no se hayan visto rastros visibles de colonización biológica que pudieran haber alertado al investigador a seleccionar otro tipo de muestra, el daño químico probablemente tendrá un impacto mayor. El deterioro químico por disolución de los elementos presentes de la fábrica de la pasta, su transformación o la cristalización de nuevos, estarían alterando todas aquellas técnicas específicas enfocadas en la identificación de fases elementales. Información que es de relevancia para la identificación de recetas pigmentarias basadas en el reconocimiento de fases elementales. Al respecto, hay que destacar que las especies reconocidas son capaces de desarrollar en un material inorgánico con escasez de nutrientes. Entonces, si se diera el caso de que algunas de las mezclas pigmentarias estuviesen constituida con materiales orgánicos ricos en carbono, como suele ocurrir en ciertas regiones de los andes (De la Fuente \& Pérez Martínez, 2008; López Milla \& Olivera de Lescano, 2007, entre otros), y hubiera presencia de agentes microbiológicos, estos indefectiblemente se alimentarían de dichos pigmentos y sesgarían los resultados.

En el caso de estudio, se corroboró mediante EDS que los sectores con evidente actividad biológica presentaban valores diferentes a aquellos sectores sin colonización o dónde esta era menor. Aunque análisis de metabolómica se requieren para reconocer cuáles son los metabolitos y que especies los producen (Gutarowska et al., 2015), se corroboró la acidificación del material y se observaron sectores con un incremento de la porosidad de la pasta por biopits microscópicos. La alteración de las proporciones de microcavidades de una pieza es una cuestión a tener presente si se pretende cuantificar su porosidad con técnicas como el nitrógeno líquido (Harry \& Johnsen, 2004). Además, una elevada producción de SPE por la actividad microbiológica directamente imposibilita observar los elementos composicionales de las pastas, tal cual se evidenció por SEM.

Colonna-Preti y Eeckhout (2014) advirtieron que el material cerámico de excavación aun desalinizado y lavado posee suficientes residuos grasos capaces de operar como nutrientes para bacterias. Los análisis de lípidos y microrestos suelen realizarse en material de excavación porque se los considera apto al no haber sido afectado por los agentes fluviales. No obstante, si se desconoce la presencia de microrganismo en la matriz sedimentaria del sitio arqueológico y en la misma pasta cerámica, los resultados corren el riesgo de verse sesgados afectando toda inferencia en base a ellos.

Algunos de los problemas en la preparación de las muestras pueden ser evitados si se escogen secciones sin colonización biológica o materiales que no se ven impactados por el biodeterioro, pero en la obtención de datos no es tan sencillo. ¿Cómo garantizar que la muestra para microscopía electrónica permitirá apreciar la matriz cerámica y sus inclusiones, no mostrando superficies repletas de SPE? Estos estudios son costosos, tanto en dinero como tiempo de investigación y no pueden ser desperdiciados. En otras palabras, es imprescindible conocer el estado de preservación real de nuestro material y los diferentes agentes y factores que lo afectan.

\section{Agentes microbiológicos como bioindicadores}

Los acápites previos presentan impactos concretos y abstractos en los materiales cerámicos arqueológicos, sugiriendo sólo aspectos perjudiciales de la presencia de agentes biológicos. No obstante, si nuestras muestras están colonizadas por estos agentes también podemos emplearlos como bioindicadores o líneas de evidencia complementaria, para abordar otro tipo de estudios arqueológicos.

\section{Procesos de formación de sitio}

Desde esta perspectiva los líquenes adheridos a material en estratigrafía operan como bioindicadores relativos de la dinámica de suelos. Como se explicó anteriormente, los líquenes son organismos simbiontes con una parte fúngica y otra fototrófica que necesitan estar a la intemperie para realizar la fotosíntesis (Kumar \& Kumar, 1999; St. Clair \& Seaward, 2004). Hallar material enterrado con evidencias de líquenes nos confirma que la matriz sedimentaria ha sido disturbada por procesos postdepositacionales y/o agentes erosivos, aun cuando no se presenten evidencias de madrigueras, túneles de insectos o presencia de vegetación. En el área de estudio, se suman a estos procesos los movimientos de suelos por obras públicas de gran envergadura que han expuesto material a la colonización biológica. El avance de la liquenología es imperioso para conocer la viabilidad de diferentes líquenes en condiciones de entierro, información que nos permitiría estimar el tiempo en que se dieron los procesos de sedimentación y erosión. Empero, el caso de estudio demostró la resistencia de los cianolíquenes a esta dinámica de suelos y que a partir de los dos años de entierro la simbiosis de hongos y cianobacterias empieza a debilitarse, desprendiéndose las cianobacterias del talo e adentrándose en el material cerámico (Soto, 2019). Al mismo tiempo, los microorganismos de la matriz sedimentaria pueden haberse trasladado a los materiales arqueológicos, activándose y desatado su deterioro una vez que son expuestos a nuevas condiciones ambientales (Colonna-Preti \& Eeckhout, 2014). En consecuencia, no se puede seguir hablando simplemente de bioturbación de la forma clásica (Schiffer, 1987) cuando existen otra infinidad de agentes biológicos que pueden producir un grave deterioro in situ de materiales arqueológicos, que continua incluso después que estos han sido extraídos del sitio. No existen materiales cerámicos de diferente clasificación, diferentes estilos o tecnologías, más susceptibles de ser biodeteriorados. Sí existe una bioreceptividad intrínseca de estos materiales en ambientes áridos debido a que las rigurosas condiciones ambientales se ven atenuadas a su interior.

La sensibilidad de estos agentes microbiológicos a cambios en la composición química de la matriz sedimentaria (Rose, 1981) también debe ser contemplada, puesto que en áreas dónde 
se han realizado actividades humanas por periodos prolongados los valores de $\mathrm{pH}$, carbono, nitrógeno, fósforo, entre otros, se ven alterados (Pingarrón et al., 2014). La presencia de materia orgánica no sólo funciona como nutriente básico para la microbiota, sino que puede estar incrementado por la presencia de microorganismos activos metabólicamente, relacionable a los resultados obtenidos por EDS en las cerámicas o al intenso poblamiento del valle durante el Periodo Medio (Soto, 2019). Esta sensibilidad en los líquenes vinculada a su crecimiento lento (Kumar \& Kumar,1999), puede estar dando cuenta de los últimos usos de áreas productivas o, viceversa, de la fijación de aquellos componentes que fueron agotados, nitrógeno y carbono, por una agricultura intensiva (Houssman et al., 2006). Los agentes microbiológicos presentan una relación sinérgica con la matriz sedimentaria, se ven condicionados por sus valores al mismo tiempo que son agentes de su alteración.

\section{Estudios paleoambientales}

La susceptibilidad de los agentes microbiológicos a cambios climáticos es bien conocida (Rose, 1981; St. Clair \& Seaward, 2004), actuando como bioindicadores de la calidad del aire y la contaminación atmosférica (Herk 2001). Se ha demostrado que el factor determinante en la colonización por líquenes del recubrimiento de morteros en ciudades romanas de Italia y España, es la variación de las condiciones ambientales, por más leve que sean (Ariño \& Saiz-Jimenez, 2004). Sólo cuando esta variabilidad es mínima, las propiedades físico-químicas del material empiezan a tener un rol más relevante. El reconocimiento de estos agentes microbiológicos puede operar como un proxy ambiental de alta precisión (Piñar et al., 2019) para los estudios enfocados en la reconstrucción paleoambiental.

Aunque esta línea de investigación debe ser indefectiblemente trabajada de forma interdisciplinar en un proyecto a largo plazo que permita construir una base de datos de referencia, tanto de la biota actual como la del pasado, hay que tener presente el grado de resolución de nuestra escala de análisis. Los análisis de la matriz sedimentaria hasta la fecha no se han realizado con microscopías electrónicas a más de x1000, sino con microscopías ópticas. Lo ideal para iniciar este tipo de estudios es mantener la escala de análisis pero incluir a los líquenes a las variables a ser analizadas.

\section{Circulación de objetos y materias primas}

Los hongos y bacterias, principalmente, se presentan como los bioindicadores más fehacientes de la historia de vida de los objetos en tanto aluden a los ambientes y regiones por los cuales estos han transitado (Piñar et al., 2019). Ciertas especies de microorganismos manifiestan extrema sensibilidad a cambios del $\mathrm{pH}$, a la presencia de ciertos nutrientes en los suelos como a condiciones climáticas, por lo que se encuentran limitadas a determinados ambientes o regiones (Rose, 1981). Similar a lo que ocurre con las diatomeas y su desarrollo exclusivamente en ambientes acuáticos. La identificación de estos agentes microbiológicos se muestra como una nueva línea de evidencia complementaria para investigaciones que estén abordando cuestiones de circulación de materias primas u objetos. Muchas veces los arqueólogos nos encontramos abocados a las decoraciones o a los estudios de pastas para vincular una pieza con una región. Si bien, se requiere del conocimiento de las especies locales de las áreas a usar como base comparativa, la identificación y tipificación de bacterias y/o hongos adaptados a cierto tipo de ambientes en sí misma ya es un dato relevante.

En el caso de estudio, todas las especies registradas se asocian a ambientes áridos, lo que es coincidente con las condiciones ambientales, pero si se hubiera reconocido una especie propia de ambientes húmedos estaría indicando que ese fragmento cerámico perteneció a una vasija que en algún momento de su historia de uso estuvo en una región con clima diferente. De la misma manera podrían llegar a identificarse fuentes particulares de arcillas que tengan presencia de algún tipo de microorganismos particular debido a la composición química específica de esa fuente. Intercalar varias líneas de evidencia es la mejor forma de aproximarnos a armar el rompecabezas del pasado.

En otras palabras, el uso de los microorganismos como bioindicadores no requiere de un completo conocimiento de la biota del área de estudio o de las diferentes regiones colindantes. No es equiparable al caso de los isótopos estables, cuyas mediciones son sesgadas si no se calibran con curvas regionales. A mayor información más precisos son los resultados, pero la falta de la misma no los hace inoperativos. Hay que tener presente que un tiesto arqueológico ya constituye un universo entero para los microorganismos, por lo que es irrisorio pretender disponer de guías de especies por regiones y mucho menos países. Es probable que los cultivos microbiológicos constituyan una alternativa provechosa y de menor costo que estudios de activación neutrónica, porque al mismo tiempo que responderían las preguntas vinculadas a proveniencia o circulación de bienes y/o materias primas, estarían dando cuenta de la presencia de agentes microbiológicos colonizando el material, y con ello, facilitando la evaluación de su estado de conservación.

\section{Conclusiones}

A pesar de que el presente escrito se basa en las reflexiones e implicancias del análisis de un caso de estudio del norte riojano, en el noroeste argentino, a lo largo de este trabajo se ha demostrado la importancia e implicancia de la colonización biológica para todo tipo de materiales cerámicos arqueológicos en ambientes áridos. Es así que los materiales cerámicos arqueológicos, por sus propiedades físicoquímicas, constituyen un material bioreceptivo para los agentes microbiológicos en ambientes hostiles. La porosidad funciona para retener la escasa humedad relativa, usualmente producto de la condensación del rocío, y como un microclima al interior de la pasta que atenúa las bruscas fluctuaciones térmicas propias de estas regiones. Además, si bien su conductividad térmica no es como la de los metales, es suficiente para retener el calor necesario para la vida microbiológica. Finalmente, la resistencia de las pastas cerámicas le permite ser trasladada por las escorrentías estacionales, a diferencia de las costras biológicas desarrolladas sobre sedimento que son socavadas perdiendo su agarre al sustrato por la erosión fluvial. De igual manera que se consideran relevantes los intensos procesos erosivos por precipitaciones estivales que crean cárcavas, alteran los cursos de ríos meandrosos e intermitentes en los valles áridos y contribuyen así a la formación de barreales y palimpsestos de materiales arqueológicos, es importante ser consciente de la incidencia de los agentes microbiológicos en los procesos formadores de sitios arqueológicos.

Si bien esta investigación se llevó a cabo sobre material 
fragmentario de superficie, se confirmó que algunas de las especies colonizando las cerámicas estaban presentes en la matriz sedimentaria, razón por la cual muy posiblemente el material estratigráfico también puede contener microorganismos en estado de latencia esperando a que condiciones adecuadas los reactiven tal cual otros casos arqueológicos han demostrado. También, se resaltó la importancia para los análisis edafológicos del conocimiento de la biota local para evitar el sesgo en la toma de muestras como en la interpretación de sus resultados. Ello alerta sobre la importancia de entender la totalidad de las condiciones ambientales del área de estudio y evaluar la incidencia de los procesos postdepositacionales en todas sus manifestaciones y escalas, en especial en ambientes áridos.

El biodeterioro registrado en los materiales cerámicos es un proceso complejo que involucra gran variedad de especies que conforman enteros microecosistemas al interior de la pasta y sobre sus superficies, retroalimentándose mutuamente y presentando en algunos casos relaciones simbióticas, las cuales forman parte del ciclo de sinergia entre la meteorización y la acción de los agentes postdepositacionales. No se reconocieron biofilm, pero un ensayo en laboratorio con $P$. aeruginosa demostró que esta bacteria es capaz de desarrollarse de ese modo a pesar de tratarse de un material inorgánico con escases y/o ausencia de carbono. La susceptibilidad de las diferentes materialidades arqueológicas a la colonización biológica no se limita al predominio de compuestos orgánicos, sino a un conjunto de factores interrelacionados en dónde las propiedades físicoquímicas intrínsecas al material y las variables ambientales desempeñan un rol central.

Se puede hablar de dos tipos de implicancias de la colonización biológica en materiales cerámicos arqueológicos y en todo tipo de bienes culturales. La primera remite al impacto físico en su preservación, el riesgo explícito y/o potencial de que algunas especies sean agentes patógenos y los potenciales impactos en investigaciones arqueométricas. La segunda, resalta la posibilidad de emplear a los agentes biológicos como líneas de evidencia complementaria en estudios arqueológicos. Se trate de implicancias concretas y observables o abstractas y potenciales, en tanto remiten a futuras investigaciones y todavía su incidencia real no ha sido sistemáticamente evaluada, sobre la relevancia de los agentes microbiológicos para la arqueología y el patrimonio cultural, es incuestionable.

Esta línea de investigación es interdisciplinar y ha sido escasamente abordada desde las ciencias arqueológicas, razón por la cual existe gran interés internacional en la mirada antropológica. Más allá de las implicancias y reflexiones aquí presentadas, queda mucho por hacerse y existen muchas materialidades y bienes patrimoniales cuya biodeterioro debe ser críticamente analizado para entender cómo repercute en el conocimiento del pasado y en los valores sociales y culturales que contiene e invoca.

\section{Agradecimientos}

A la Dra. Adriana Callegari (IA, UBA) por su dirección en mí licenciatura. Al Dr. Alfredo Passo (INIBIOMA-CONICET, Universidad Nacional de Comahue, Argentina) y al Dr. Matthias Schultz (Instituto de Ciencias de las Plantas y Microbiología, Universidad de Hamburgo, Alemania) por el trabajo conjunto en la identificación taxonómica de los líquenes. A la Dra. Patricia Guiamet (INIFTA-UNLP-CONICET, Argentina) por los saberes enseñados, la codirección de mi licenciatura y el trabajo articulado en el aislamiento y tipificación de microorganismos.
A la Mg. Laura Staropoli (ArqueoLab-UBA) por sus comentarios al manuscrito. Finalmente a los evaluadores por la revisión y observación para que el manuscrito se enriqueciera. Sin embargo, lo presentado es de mi responsabilidad. Esta investigación se realizó con el financiamiento UBACyT F. 20020130100013BA y Proyecto de Incentivos 11N 713 UNLP.

\section{Notas}

1 La liquenología es la rama de las ciencias biológicas especializada en el estudio e identificación taxonómica de líquenes, organismos complejos que constituyen una simbiosis entre una parte fototrófica, algas y/o cianobacterias, y otra fúngica. El Dr. Schultz se especializa en identificación taxonómica de cianolíquenes.

2 La microbiología es otra subdisciplina de la biología enfocada en el estudio de aquellos organismos no visibles a ojo desnudo (algas, hongos, bacterias, parásitos y virus), debido a sus ínfimas dimensiones. La Dra. Guiamet es especialista en el deterioro microbiológico de bienes culturales e industriales.

3 En la actualidad existen dos métodos para identificar microorganismos: técnicas fenotípicas que implican la realización de cultivos tradicionales (sólo identifican una fracción de los microrganismos activos y tienen menor capacidad de diferenciación de especies) o técnicas genotípicas moleculares (reconocen amplia variabilidad de especies activas o en estado de latencia) de mayor coste (Gutarowska 2016).

4 Las costras biológicas (soil crust) son comunidades microbianas complejas que comprenden más del cincuenta por ciento de la biota de ambientes áridos y semi-áridos. Una de sus funciones es operar como elementos estabilizadores de suelos (Mager y Thomas 2011).

5 Nuevos resultados han permitido identificar y tipificar gran cantidad de bacterias y hongos en las cerámicas del área de estudio mediante la aplicación de metagenómica, técnica avanzada de microbiología molecular, que serán tratados en otra publicación actualmente en confección.

\section{Bibliografía}

Acevedo, V., López, M., Callegari, A., Freire, E., Halac, E., Polla, G. \& Reinoso, M. (2015). Estudio tecnológico de diseños "estilo Aguada" realizados sobre fragmentos de cerámicos. En A. Piffereti \& I. Dotzal (Eds.) Arqueometría argentina. Metodologías científicas aplicadas al estudio de los bienes culturales. Datación, caracterización, prospección y conservación (pp. 109-125). Buenos Aires: Aspha.

Allsopp, D., Seal, K. \& Gaylarde, C. (2004). Introduction to Biodeterioration, 2da ed. Cambridge: Cambridge University Press. Doi: 10.1017/CBO9780511617065

Altieri, A., Laurenti, M.C \& Roccardi, A. (1999). The conservation of archaeological sites: materials y techniques for shortterm protection of archaeological remains. En Proceedings of the 6th international conference, non-destructive testing $y$ microanalysis for the diagnostics and conservation of the cultural and environmental heritage (pp. 673-687). Roma: Agfa.

Ariño, X. \& Sainz-Jimenez, C. (2004). Lichens of different mortars at archaeological sites in southern Spain. En L. St. Clair \& M. Seaward (Eds.), Biodeterioration of stone 
surfaces: lichens and biofilms as weathering agents of rocks and cultural heritage (pp.165-179). Inglaterra: Kluwer Academic Publisher y Springer Science; Business Media.

Ascaso, C., Wierzchos, J., Souza Egipsy, V., De Los Ríos, A. \& Delgado Rodríguez, J. (2002). In situ evaluation of the biodeteriorating action of microorganisms and the effects of biocides on carbonate rock of the Jeronimos Monastery (Lisbon). International Biodeterioration \& Biodegradation 49: $1-12$.

Büdel, B. (1987). Zur Biologie und Systematik der Flechtengattung Heppia und Peltula im südlichen Afrika. Bibliotheca Lichenologica, 23, 1-105.

Cabrera, A. (1976). Regiones fitogeográficas argentinas. Enciclopedia argentina de agricultura y jardinería, 2, 1-85.

Callegari, A., Soto, D. \& de Acha, S. (2017). El arte rupestre de la localidad arqueológica La Cuestecilla, norte de la provincia de La Rioja. Cuadernos del Instituto Nacional de Antropología y Pensamiento Latinoamericano - Series Especiales, 5 (1), 1-23.

Callegari, A., Spengler, G. de Acha, S. (2019). Estrellas riojanas. Geoglifos del norte de la provincia de La Rioja, Argentina. Boletín del Museo Chileno de Arte Precolombino, 24 (1), 1134.

Callegari, A., Spengler, G., Gonaldi, M. \& Aciar, E. (2013). Construcción del paisaje en el valle de Antinaco, departamento de Famatina, provincia de La Rioja (ca. 0-1300 AD). En A. Nielsen, I. Gordillo \& J. M. Vaquer (Eds.), Tradición e identidad. Arqueología y espacialidad. Enfoques, métodos y aplicación (pp. 303-344). Quito: Abya Yala.

Callegari, A., Spengler, G. \& Rodríguez, G. (2015). La complejidad social en Aguada. El caso del valle de Antinaco, departamento de Famatina, norte de la provincia de La Rioja (Argentina). Arqueología - Dossier 21, 111-137.

Colonna-Preti, K. \& Eeckhout, P. (2014). The bacteriological contamination of archaeological ceramics: an example from Pachacamac (Perú). En H. Roemich \& K. van Lookeren Campaign (Eds.), Recent Advances in Glass, Stained Glass, and Ceramics Conservation (pp. 205-213). Londres: SPA Uitgevers.

Coutinho, M., Miller, A., Martin Sanchez, P., Mirão, J., Gómez Bolea, A., Machado Moreira, B., Cerqueira Alves, L., Jurado, V., Sainz Jimenez, C., Lima, A., Phillips, A., Pina. F. \& Macedo, M. (2016). A multiproxy approach to evaluate biocidal treatments on biodeteriorated majolica glazed tiles. Environmental Microbiology, 18 (12), 4794-4816.

Cremonte, B. \& Pereyra Domingorena, L. (2013). Atlas de pastas cerámicas arqueológicas. Petrografía de estilos alfareros del NOA. San Salvador de Jujuy: Universidad Nacional de Jujuy.

De la Fuente, N. (1972). Investigaciones arqueológicas en la quebrada de Chañarmuyo, provincia de La Rioja. Antiquitas. Boletín de la Asociación Amigos del Instituto de Arqueología, $15,2-11$.

De la Fuente, N. (2002). Arqueología de Famatina: reseña de la arqueología de Famatina y su relación con zonas aledañas. Córdoba: Edición particular.
De la Fuente, G. \& Pérez Martínez, M. (2008). Estudiando pinturas en cerámicas arqueológicas "Aguada Portezuelo" ( $c a$. 600900 AD) del Noroeste Argentino: nuevos aportes a través de una aproximación arqueométrica por microespectroscopía de Ramán (MSR). Intersecciones en Antropología, 9, 173-186.

De los Ríos, A., Cámara, B., García Del Cura, M., Rico, V., Galván, V. \& Ascaso, C. (2009). Deteriorating effects of lichen y microbial colonization of carbonate building rocks in the romanesque churches of Segovia (Spain). Science of The Total Environment, 407 (3), 1123-1134. Doi:10.1016/j. scitotenv.2008.09.042.

Fazio, A., Cavicchioli, A., Penna, D., Chambergo, F. \& De Faria, D. (2015). Towards a better comprehension of biodeterioration in earthen architecture: study of fungi colonisation on historic wall surfaces in Brazil. Journal of Cultural Heritage, 16, 934-938.

Gaylarde, C. (2013). Biodeterioration, biodegradation, bioremediation. En J. Verran(Ed.), An atlas of biodeterioration (pp. 7). Inglaterra: International Biodeterioration and Biodegradation Society.

Gonaldi, M., Callegari, A., Spengler, G., Aumont, S., Rodriguez, G. \& Wisnieski, G. (2008). El patrimonio arqueológico del Norte del dto. de Famatina, y otros temas generales de arqueología. Buenos Aires: Asociación de Amigos del Instituto Nacional de Antropología (AINA).

Gorbushina, A. (2007). Minireview: life on the rocks. Environmental Microbiology, 9 (7), 1613-1631.

Gorbushina, A., Boettcher, M., Brumsack, H., Krumbein, W. \& Vendrell Saz, M. (2001). Biogenic forsterite and opal as a product of biodeterioration and lichen stromatolite formation in Table Mountain Systems (Tepuis) of Venezuela. Geomicrobiology Journal, 18, 117-132.

Gorbushina, A. \& Broughton, W. (2009). Microbiology of the atmosphere-rock interface: how biological Interactions y physical stresses modulate a sophisticated microbial ecosystem. Annual Review of Microbiology, 63 (1), 431-450. Doi:10.1146/annurev.micro.091208.073349.

Gromaire, M., van de Voorde, A., Lorgeoux, C. \& Chebbo, G. (2015). Benzalkonium runoff from roofs treated with biocide products - in situ pilot-scale study. Water Research, 81, 279287.

Guiamet, P., Oliva, F, Gallego, M. \& Gómez De Saravia, S. (2008). Biodeterioration: an applied case for rock art in the Ventania Hill System (Buenos Aires, Argentina). O Público e o privado, 12, 105-120.

Guiamet, P., Pietrzak, K., Gutarowska, B., Otlewska, A., Igareta, A., Teileche, T. \& Batistoni, P. (2015). Textiles de la puna Argentina. Identificación del biodeterioro a través de diferentes técnicas. En O. Martín Palacios, C. Vázquez \& N. Ciarlo (Eds.) Patrimonio cultural: la gestión, el arte, la arqueología y las ciencias exactas aplicadas (pp. 259-265). Buenos Aires: Nuevos Tiempos.

Guiamet, P.; Soto, D. \& Schultz, M. (2019). Bioreceptivity of archaeological ceramics in an arid region of northern Argentina. International Biodeterioration \& Biodegradation, 


\section{1, 2-9. Doi:10.1016/j.ibiod.2018.10.003.}

Guild, S. \& Macdonald, M. (2004). Mould prevention and collection recovery: guidelines for heritage collections. Technical Bulletin 26. Canadian Conservation Institute, Canada.

Guillite, O. (1995). Bioreceptivity: a new concept for building ecology studies. Science of The Total Environment, 167, 215-220.

Gutarowska, B. (2016). A modern approach to biodeterioration assessment and the disinfection of historical book collections. Lodz: OPRAWA.

Gutarowska, B., Celikkol Aydin, S., Bonifay, V., Otlewska, A., Aydin, E., Oldham, A., Brauer, J., Duncan, K., Adamyak, J., Sunner, J. \& Beech, I. (2015). Metabolomic and highthroughput sequencing analysis-modern approach for the assessment of biodeterioration of materials from historic buildings. Frontiers in Microbiology, 6. Doi:10.3389/ fmicb.2015.00979.

Harry, K. \& Johnson, A. (2004). A non-destructive technique for measuring ceramic porosity using liquid nitrogen. Journal of Archaeological Sciences, 31, 1567-1575.

Herk, C. (2001). Bark pH and susceptibility to toxic air pollutants as independent causes of changes in epiphytic lichen composition in space and time. The Lichenologist, 33, 419441.

Housman, D., Powers, H., Collins, A. \& Belnap, J. (2006). Carbon y nitrogen fixation differ between successional stages of biological soil crusts in the Colorado Plateau y Chihuahuan Desert. Journal of Arid Environments, 66 (4), 620-634.

Hueck, J. (1968). The biodeterioration of materials - an appraisal. En: A. H. Walters \& J. S. Elphick (Eds.), Biodeterioration of materials (pp. 6-12). Londres: Elsevier.

Jans, M. (2008). Microbial corrosion of bone - a review. En M. Wisshak \& L. Tapanila (Eds.), Current Developments in Bioerosion. Erlangen Earth Conference (pp. 397-413). Berlin: Springer.

Jans, M., Nielsen Marsh, C., Smith, C., Collins, M. \& Kars, H. (2004). Characterisation of microbial attack on archaeological bone. Journal of Archaeological Science, 31 (1), 87-95. Doi:10.1016/j.jas.2003.07.007.

John, A., Tomas, M., Cadnum, J., Mana, T., Jencson, A., Shaikh, A., Zabarsky, T., Wilson, B. \& Donskey, C. (2016). Are health care personnel trained in correct use of personal protective equipment? American Journal of Infection Control, 44 (7), 840-842. Doi:10.1016/j.ajic.2016.03.031.

Kang, J., O’Donnell, J., Colaianne, B., Bircher, N., Ren, D. \& Smith, K. (2017). Use of personal protective equipment among health care personnel: results of clinical observations and simulations. American Journal of Infection Control, 45, (1), 17-23. Doi:10.1016/j.ajic.2016.08.011.

Kakakhela M., Wua, F., Gu, J., Fenga, H., Shahd, K. \& Wang, W. (2019). Controlling biodeterioration of cultural heritage objects with biocides: a review. International Biodeterioration \& Biodegradation, 143.
Kumar, R. \& Kumar, A. (1999). Biodeterioration of stone in tropical environments. An overview. Series Research in conservation. The Getty Conservation Institute, Ottawa.

Mager, D. \& Thomas, A. (2011). Extracellular polysaccharides from cyanobacterial soil crusts: a review of their role in dryland soil processes. Journal of Arid Environments, 75 (2), 91-97. Doi: 10.1016/j.jaridenv.2010.10.001.

Michalski, S. (2006). Preservación de las colecciones. En P. J. Boylan (Ed.), Cómo administrar un museo: manual práctico, pp. 51-90. ICOM-UNESCO, Paris.

Moreno, P. \& Egea, M. (1992). Studies on the Anema-ThyreaPeccania complex from the southeastern Iberian Peninsula y northern Africa. Acta Botanica Barcinonensia, 41, 1-66.

Moskal Del Hoyo, M., Wachowiak, M. \& Blanchette, R. (2010). Preservation of fungi in archaeological charcoal. Journal of Archaeological Science, 37, 2106-2116.

Nash III, T., Ryan, B., Gries, C. \& Bungartz, F. (Eds.). (2002). Lichen Flora of the Greater Sonoran Desert Region. Arizona: Arizona State University.

Nishiura, T., Okabe, M. \& Kuchitsu, N. (1994). Study on the conservation treatment of Irimizu Sanjusan Kannon cleaning y protective treatment of a marble buddha image. Hozon Kagaku, 33, 67-72.

Lavin, P., Gómez De Saravia, S. \& Guiamet, P. (2014). An environmental assessment of biodeterioration in document repositories. Biofouling, 30, 561-569.

López Milla, A. \& Olivera de Lescano, P. (2007). Caracterización de pigmentos aplicados en material arqueológico de la cultura Chincha por fluorescencia de rayos X y microscopía electrónica de transmisión. Revista de la Sociedad Química del Perú, 73 (1), 3-17.

Luján Roca, D. (2014). Pseudomonas aeruginosa: un adversario peligroso. Acta Bioquímica Clínica Latinoamericana, 48 (4), 465-474.

Papida, S., Murphy, W. \& May, E. (2000). Enhancement of physical weathering of building stones by microbial populations. International Biodeterioration \& Biodegradation, 46 (4), 305-317.

Pattron, D. (2006). Aspergillus, health implication and recommendations for public health food safety. Internet Journal of Food Safety, 8, 19-23.

Pietrzak, K., Puchalski, M., Otlewska, A., Wrzosek, H., Guiamet, P., Piotrowska, M. \& Gutarowska, B. (2017). Microbial diversity of pre-columbian archaeological textiles and the effect of silver nanoparticles misting disinfection. Journal of Cultural Heritage, 23, 138-147. Doi:10.1016/j. culher.2016.07.007.

Pietrasiak, N., Regus, J., Johansen, J., Lam, D., Sachs, J. \& Santiago, L. (2013). Biological soil crust community types differ in key ecological functions. Soil Biology y Biochemistry, 65, 168-171.

Pingarrón, L., Ortiz Butrón, A. \& Pecci, A. (2014). Los residuos químicos. Indicadores arqueológicos para entender la producción, preparación y consumo de alimentos en 
mesoamérica. Anales de Antropología, 48 (1), 201-239.

Piñar, G., Poynter, C., Tafer, H. \& Sterflinger, K. (2019). A time travel story: metagenomic analyses decipher the unknown geographical shift and the storage history of possibly smuggled antique marble statues. Annals of Microbiology, 69, 1001-1021. Doi: 10.1007/s13213-019-1446-3.

Rajkowska, K., Otlewska, A., Guiamet, P., Wrzosek, H. \& Machnowski, W. (2020). Pre-columbian archaeological textiles: a source of Pseudomonas aeruginosa with virulence attributes. Applied siences, 10, 116.

Rose, A. (Ed.). (1981). Economic microbiology vol. 6: Microbial biodeterioration. Londres-Nueva York-Toronto-Sydney-San Francisco: Academic Press.

Rutala, W. \& Weber, D. (Eds.). (2017). Guideless for disinfection. Healthcare Infection Control Practices Advisory Committee (HICPAC), Carolina del Norte.

Sánchez Del Junco, A., Moreno, D.A., Ranninger, C., OrtegaCalvo, J.J, \& Sáiz Jiménez, C. (1992). Microbial induced corrosion of metallic antiquities y works of art: a critical review. International Biodeterioration \& Biodegradation, $29,367-375$.

Schiffer, M. (1987). Formation processes of the archaeological record. Utah: University of Utah Press.

Schultz, M. (2009). An overview of Lichinella in the Southwestern United States and Northwestern Mexico, the new species Lichinella granulosa. Bryologist, 108, 567-590.

Schultz, M. \& Büdel, B. (2002). Key to the genera of the Lichinaceae. The Lichenologist, 34(1), 39-62.

Seaward, M. (1988). Lichen damage to ancient monuments: a case study. The Lichenologist, 20(3), 291-295.

Seaward, M. (2003). Lichens, agents of monumental destruction. Microbiology Today, 30, 110-113.

Silver, C. \& Wolbers, R. (2004). Lichen encroachment onto rock art in Eastern Wyoming: conservation problems y prospects for treatment. En L. St.Clair \& Mark R. (Eds.), Biodeterioration of stone surfaces (pp. 115-128). Dordrecht: Springer Netherlands.

Soto, D. (2015). Deterioro de fragmentos cerámicos por la acción de líquenes. En A. Piffereti \& I. Dotzal (Eds.), Arqueometría argentina. Metodologías cientificas aplicadas al estudio de los bienes culturales. Datación, caracterización, prospección y conservación (pp. 207-220). Buenos Aires: Aspha.

Soto, D. (2019). Biodeterioro de cerámicas arqueológicas de superficie, valle de Antinaco central, La Rioja. (Tesis de Licenciatura). Departamento de Antropología, Facultad de Filosofía y Letras, Universidad de Buenos Aires, Buenos Aires.

Soto, D. \& Guiamet, P. (2017). Aplicabilidad de la conservación preventiva a la cerámica arqueológica impactada por biodeterioro. Cuadernos del Instituto de Antropología y Pensamiento Latinoamericano - Series Especiales, 5 (2), 71-90.

Soto, D., Guiamet, P. \& Callegari, A. (2017). Biodeterioro de cerámica arqueológica de superficie por microorganismos de climas áridos y semi-áridos en el valle central de Antinaco, La Rioja. En A. Rochetti, F. Rivero \& D. Reinoso (Eds.), Investigaciones Arqueométricas: técnicas y procesos (pp. 121-137). Buenos Aires: Aspha.

Soto, D., Otlewska, A., Rajkowska, K., Schultz, M., Guiamet, P. \& Gutaroska, B. (2019). Análisis de procesos postdepositacionales biológicos mediante SEM y metagenómica sobre cerámica superficial en Rio Grande de Valle Hermoso (norte de La Rioja, Argentina). En Actas VI Congreso Latinoamericano de Arqueometría (pp. 53). Bogotá: Universidad de los Andes.

Soto, D., Otlewska, A., Rajkowska, K., Gutarowska, B. \& Guiamet, P. (2020). Monitoring bioadhesion and biofilm formation within biopits in archaeological potsherds by SEM-EDS. Microscopy \& Microanalysis, 26 (1), 119-110. Doi: 10.1017/S143192762000077X

St. Clair, L. \& Seaward, M. (Eds.). (2004). Biodeterioration of stone surfaces: lichens y biofilms as weathering agents of rocks y cultural heritage. Inglaterra: Kluwer Academic Publisher y Springer Science + Business Media.

Sterflinger, K. 2010. Fungi: their role in deterioration of cultural heritage. Fungal Biology Reviews, 24, 47-55.

Sterflinger, K. \& Piñar, G. (2013). Microbial deterioration of cultural heritage and works of art - tilting at windmills? Applied Microbiology \& Biotechnology, 97, 9637-9646. Doi: 10.1007/s00253-013-5283-1.

Strang, T. \& Kigawa, R. (2009). Combatting Pests of Cultural Property. Technical Bulletin 29. Canadá: Canadian Conservation Institute.

Strzelczyk, A., Banach, L. \& Kuroska, A. (1997). Biodeterioration of archaeological leather. International Biodeterioration \& Biodegradation, 39 (4), 301-309.

Vaillant Callol, M. (2013). Biodeterioro del patrimonio histórico documental. Alternativas para su erradicación y control. Rio de Janeiro: Museu do Astronomia e Ciencias Afins y Fundación Casa do Rui Barbosa.

Valgañón, V. (2008). Biología aplicada a la conservación y restauración. Síntesis, Madrid.

Verran, J. (Ed.). 2013. An Atlas of Biodeterioration. Inglaterra: International Biodeterioration and Biodegradation Society.

Videla, H. \& Giudice, C. (Eds.). (2001). Jornadas cientifico tecnológicas sobre prevención y protección del patrimonio cultural iberoamericano de los efectos del biodeterioro ambiental. Memorias. La Plata: CYTED.

Warcheid, T. \& J. Braams. (2000). Biodeterioration of stone: a review. International Biodeterioration \& Biodegradation, 46 (4), 343-368.

Wood, W. \& D. Johnson. (1978). A survey of disturbance processes in archaeological site formation. En M. Schiffer (Ed.), Advances in Archaeological Method and Theory, vol. I (pp. 315-381). New York: Academic Press.

Zarate, M., González de Bonaveri, M., Flegenheimer, N. \& Bayón, C. (2000-2002). Sitios arqueológicos someros: 
el concepto de sitio de estratigrafía y sitio de superficie. Cuadernos del Instituto Nacional de Antropología y Pensamiento Latinoamericano, 19, 635-653. 